\title{
Concurrent tolerance allocation and scheduling for complex assemblies
}

\author{
${ }^{*}$ K . Geetha ${ }^{1}$, D. Ravindran ${ }^{2}$, M.Siva Kumar ${ }^{3}$, and M. N. Islam ${ }^{4}$ \\ ${ }^{I}$ Department of Mechanical Engineering, SACS M.A.V.M.M Engineering College, Alagarkovil, Madurai - \\ 625301, Tamilnadu, India \\ ${ }^{2}$ National Engineering College, K.R. Nagar, Kovilpatti 628 503, Tamilnadu, India \\ ${ }^{3}$ Sree Sowdambika College of Engineering, Chettikurichi-626 134, Aruppukottai, Tamilnadu, India \\ ${ }^{4}$ Department of Mechanical Engineering, Curtin University, GPO Box U 1987, Perth WA 6845, Australia
}

\begin{abstract}
Traditionally, tolerance allocation and scheduling have been dealt with separately in the literature. The aim of tolerance allocation is to minimize the tolerance cost. When scheduling the sequence of product operations, the goal is to minimize the makespan, mean flow time, machine idle time, and machine idle time cost. Calculations of manufacturing costs derived separately using tolerance allocation and scheduling separately will not be accurate. Hence, in this work, component tolerance was allocated by minimizing both the manufacturing cost (sum of the tolerance and quality loss cost) and the machine idle time cost, considering the product sequence. A genetic algorithm (GA) was developed for allocating the tolerance of the components and determining the best product sequence of the scheduling. To illustrate the effectiveness of the proposed method, the results are compared with those obtained with existing wheel mounting assembly discussed in the literature.
\end{abstract}

Keywords: Tolerance allocation; Scheduling; Lagrange's multiplier method; Genetic algorithm; Tolerance cost model; Tolerance machining time model; Quality loss cost

\section{Introduction}

There has been extensive research on tolerance allocation due to its relationship with product cost, quality, and functionality. Tolerance allocation involves allocating a component's tolerance based on its known critical dimension tolerance to meet the functional requirements of a product. There are an infinite number of combinations of component part tolerance values within process tolerance limit that can satisfy functional 
equations. However, some combinations of part tolerances are better than others. The aim of tolerance allocation is to compute the best possible combination of component part tolerances based on a given set of objectives associated constraints.

Methodologies: Various methodologies have been used to solve the tolerance allocation problem in the literature. The most frequent methods, namely Lagrange multiplier, heuristics, and metaheursitic methods, are dealt with in the following section.

Lagrange multiplier method: This method is the most popular among analytical methods for allocating the tolerances of component parts for a known assembly tolerance value. It is most suited to single-process optimization problems. This method eliminates the need for multiple-parameter iterative solutions and allows consideration of alternative costtolerance models. It can handle both worst-case and statistical tolerance accumulation models $[1-6]$. Details of the available models are discussed later in this section. The drawbacks that limit its usage are (i) the allocated tolerance values may be beyond the process precision limits, (ii) it cannot be easily adopted to alternative process selection; and (iii) it is a time-consuming and tedious process. Siva Kumar et al. [7] developed a closedform equation for tolerance allocation and compared its performance with that of Lagrange multiplier method

Heuristic method: In this method, the best combination of component part tolerances is determined using nonmathematical techniques, such as rules of thumb, past practices, and current standards [8-9]. As this method is only suited to limited cases, very few studies have used it to solve optimum tolerance allocation problems. However, a considerable number of studies have used other methods, such as the Branch and Bound algorithm [10] and Design of Experiments [11], to minimize the manufacturing costs of assemblies.

Metaheuristic method: In this method, near optimal allocated tolerances of component parts are obtained by dividing the process tolerance limits into a number of discrete points and randomly selecting a discrete tolerance for each component. The assembly tolerance is then determined with a tolerance accumulation model. The mathematical function and its constants of tolerance cost models are well known before the allocation. Two metaheuristic methods used extensively in the literature are simulated annealing [12] and genetic algorithms (GAs) [1, 13-22]. 
Cost function model: Various cost-function models have been proposed to calculate manufacturing costs. These include reciprocal [23], reciprocal squared [24], reciprocal power [25], exponential [26], reciprocal power/exponential hybrid, polynomial and fourthorder polynomial [27], reciprocal power with setup cost [2], and exponential with constant [28]. These functions can be classified into two categories: a discrete cost function (DCF) and a continuous cost function (CCF). DCF models [2, 29-32] have a relatively large number of model fitting errors, do not consider the value range of cost tolerance curves, and require manual formulation. Therefore, most studies have focused on the CCF tolerance model, which provides a closed-form solution to the optimization problem.

Taguchi introduced the concept of quality loss of a product. According to this concept, all the critical parameters (including the dimensions) of a product should be at their target values to ensure the product's best performance. If parameters deviate from their target values, the performance of the product deteriorates, and the product loses quality. A large number of studies have considered the sum of quality loss and manufacturing cost as an objective function [13, 30-31, 33-43].

Tolerance accumulation model: The tolerance accumulation model is a mathematical model that estimates the combined effect of component part tolerances on assembly tolerance. A number of tolerance accumulation models are available, and they are classified into two groups: (i) worst-case (WC) models and (ii) statistical models. The WC tolerance accumulation model considers the possibility that all the component part dimensions are at their extreme limits (i.e., maximum or minimum) simultaneously; thus, it is based on the worst-case scenario. Statistical tolerance accumulation models are based on the premise that the chance that all the component part dimensions will be at their extreme limits simultaneously is very small. Consequently, a statistical model places little significance on dimensions that have a low probability of occurring. As a result, individual tolerance values are greater when a statistical model is applied than when a WC model is applied. Statistical tolerance accumulation, such as the root sum square (RSS) method, has been used by a number of researchers [5-6, 31-33, 44].

Example product type: The ability of tolerance allocation methods to determine tolerance differs according to the product type. For example, the Lagrange multiplier 
method is more suited to a simple product than a complex product. Only a few authors [1315, 66-67, 33] have considered simple assembly products comprised of only two mating component parts as an example problem. To evaluate functional performance requirements, most researchers have focused on complex assemblies that have several critical dimensions and are controlled simultaneously within certain variation ranges $[1,4-5,10,12,16,22,28$, $36,45-56]$. A relatively small number of authors have examined nonlinear assembly products that consist of more than two components and are arranged nonlinearly [1-2, 10, 17-19, 32, 40, 57].

Process planning and scheduling: Process planning and scheduling functions play a vital role in the profitability, utilization, and delivery time of a product [58]. The method proposed by the authors was applicable to Holonic manufacturing system with dynamic changes in volume and a variety of products. Xinyu et al. [59] suggested a GA-based approach for the integration and optimization of process planning and scheduling. Li et al. [60] developed three strategies (i.e., Pareto, Nash, and Stackelberg) for computerautomated process planning and scheduling in a systematic way. Guo et al. [61] used both a combinatorial optimization model and a modern evolutionary algorithm, the particle swarm optimization (PSO) algorithm, to solve integrated process planning and scheduling problems. Hengyun et al. [62] proposed a particle swam algorithm to minimize production makespan. Xinyu et al. [63] developed a hybrid approach (a GA and a local search strategy) to solve integrated process planning and scheduling problems. Xinyu et al. [64]introduced an integrated process planning and scheduling mathematical model.

In the literature, tolerance allocation and scheduling problems are usually dealt with separately. Many papers of tolerance allocation have focused on either minimizing the tolerance cost $[1-6,8-13,15-29,31-32$,$] or minimizing the tolerance cost and quality loss$

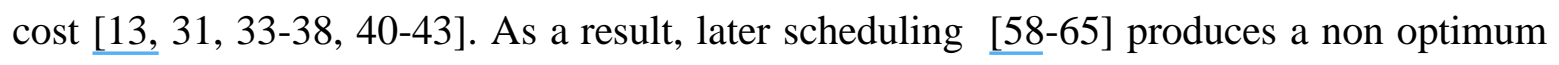
solution because the machining time and processing time of a component play a vital role in the scheduling process, which depends on the allocated tolerance of the components. Considering the tolerance allocation and scheduling separately provides misleading information about the manufacturing cost because tolerance allocation aims to minimize the tolerance cost based on the distribution of tolerance among the components of an assembly. 
However, in scheduling, the machining time plays a vital role in determining the machine idle time cost. Only a few authors $[14,36]$ have considered both tolerance costs and machining time when allocating tolerance to components. No significant effort has been made to simultaneously address tolerance allocation in the context of job-shop scheduling. Therefore, in the present study, both the tolerance cost and machine idle time cost were optimized by considering the component/operation sequence. Singh et al. [28], Prabhaharan et al. [17], Singh et al. [46], Sivakumar et al. [47], and Li et al. [63] showed that the GA provided a good solution to tolerance allocation and scheduling problems as compared with other optimization techniques. The ability of a GA to identify different solutions, given the same objective value, offers engineers a range of solutions from which they can then select the optimal one. Moreover, realizing the complexity of the problem, a GA algorithm is introduced both in allocating the best tolerance for each component of an assembly and in obtaining the best product sequence.

\section{Problem Definition}

Heavy competition in the global market forces manufacturers to reduce their manufacturing costs and improve their productivity. It is a challenging task for engineers to find the ways and means to solve the above problem. Selection of tolerance within the known process tolerance limits in a given process-machine combination influences the manufacturing cost and the productivity of the known complex assembly's critical tolerance. Infinite number of tolerance values between the process tolerance limits makes the problem a non polynomial hard problem. Besides the tolerance cost, the specified

tolerance values determine the machining time required to make the component in a machine. The sequence of operations performed on each machine determines the idle time of all the other machines. Therefore, the problem of the sequence of operations is treated as a non polynomial hard problem. 


\section{Mathematical Formulation}

The allocation of tolerance among the components of an assembly affects the manufacturing cost and machining time for a given tolerance-cost and tolerance-machining time relationship. The sequence of the product/operation to be performed on a specified machine influences other factors, including the makespan, mean flow time, machine idle time, machine idle time, and cost. The objective of the proposed method, represented in Eq. (1), is to minimize the sum of the manufacturing cost and the total machine idle time cost. The reciprocal tolerance cost model and worst-case method are used in the proposed method to allocate component's tolerance. The sum of the tolerance cost and the quality lost cost is expressed in Eq. (2). The tolerance cost is determined using Eq. (3), where the tolerances are allocated using a GA.

$$
\begin{aligned}
& Z=C_{M C}+C_{I T C} \\
& C_{M C}=C_{T T C}+C_{Q L} \\
& C_{T C i}=\eta_{i}\left(a_{i}+\frac{b_{i}}{t_{i}}\right) \\
& M T_{i}=\eta_{i}\left(X_{i}+\frac{Y_{i}}{t_{i}}\right) \\
& C_{T T C}=\sum_{i=1}^{n c} C_{T C i} \\
& C_{Q L}=\frac{C_{R C}}{\Delta^{2}}(y-m)^{2} \\
& C_{I T C}=\sum_{j=1}^{n m} I T_{j} I C_{j} \\
& t_{a s y}=\sum_{i=1}^{n c} t_{i}
\end{aligned}
$$

Constraints:

$$
\begin{aligned}
& t_{a} \geq \sum_{i=1}^{n c} t_{i} \\
& t_{\text {min }} \leq t_{i} \leq t_{\text {max }}
\end{aligned}
$$


Where,

$\begin{array}{ll}Z & \text { - Objective function } \\ C_{M C} & \text { - Manufacturing cost in } \$ \\ C_{I T C} & \text { - Total idle machine time cost } \\ C_{T C i} & \text { - Tolerance cost of the } i^{\text {th }} \text { component in } \$ \\ C_{Q L} & \text { - Cost of quality loss in } \$ \\ \eta_{i} & \text { - Efficiency factor for the } i^{\text {th }} \text { component } \\ a_{i}, b_{i} & \text { - Cost function constant for the } i^{\text {th }} \text { component } \\ X_{i}, Y_{i} & \text { - Time function constant for the } i^{\text {th }} \text { component } \\ t_{i} & \text { - Allocated tolerance for the } i^{\text {th }} \text { component } \\ C_{R C} & \text { - Cost of repairing the product in } \$ \\ y & \text { - Target value in mm } \\ m & \text { - Deviation from the target in mm } \\ \Delta & \text { - Required specification of the product in mm } \\ I T_{j} & \text { - } j^{\text {th }} \text { Machine idle time in min } \\ I C_{j} & \text { - } j^{\text {th }} \text { Machine idle time cost in } \$ \\ n c & \text { - Number of components } \\ n m & \text { - Number of machines } \\ M T_{i} & \text { - Machining time of the } i^{\text {th }} \text { component } \\ t_{a} & \text { - Given assembly tolerance in mm } \\ t_{a s y} & \text { - Calculated assembly tolerance in mm } \\ t_{m i n} & \text { - Minimum process tolerance in mm } \\ t_{m a x} & \text { - Maximum process tolerance in mm }\end{array}$

\section{Methodology}

The proposed method consists of two stages: (i) the allocation of tolerance for each operation based on a known assembly tolerance value and computation of the individual component's tolerance cost and machining time and (ii) determining the best product sequence and its total machine idle time cost. A GA is implemented in both stages to achieve the objective value. In the first stage, the tolerance for each operation/component $\left(t_{i}\right)$ is selected randomly from the process tolerance limits using Eq. (11). The assembly tolerance $\left(t_{\text {asy }}\right)$ is calculated using Eq. (8) based on the worst-case method and checked against the known value. If the constraint given in Eq. (9) is satisfied, then the tolerance cost $\left(\mathrm{C}_{T C i}\right)$ based on the reciprocal tolerance cost model and machining time $\left(M T_{i}\right)$ for each $t_{i}$ are calculated using Eq.(3) and (4), respectively. The total tolerance cost and the quality loss cost are determined using Eq. (5) and (6), respectively. In the second stage, the best component sequence is determined according to the minimum machine idle time cost using 
Eq. (7). Using the concurrent tolerance allocation and scheduling, the best tolerances of the components/operations, taking account of the sum of the tolerance cost, quality loss cost, and the machine idle time cost, is obtained, along with the best product sequence. The scheme for the proposed method is shown in Figure 1.

$$
t_{i}=t \min _{i}+\operatorname{rand}() *\left(t \max _{i}-t \min _{i}\right)
$$

\section{Numerical Illustration}

To demonstrate the proposed method, it was initially applied to an existing problem (wheel-mounting assembly) discussed by Geetha et al. [36], where the product sequence is not considered. The components of the assembly are shown in Figure 2, and its manufacturing details are presented in Tables 1 and 2, respectively. Eq. (12) and (13) represent the critical dimensions, and Eq. (14) and (15) represent the tolerances of the critical dimensions. The sum of the tolerance of each operation to obtain the critical dimensions Y1 and Y2 is calculated using Eq. (16) and (17).

$Y 1=X 2-X 4$

$Y 2=X 5-X 1-X 2-X 3$

$t_{Y 1}=t_{X 2}+t_{X 4}$

$t_{Y 2}=t_{X 1}+t_{X 2}+t_{X 3}+t_{X 5}$

$t_{Y 1}=t_{O 3}+t_{O 7}+t_{O 8}$

$t_{Y 2}=t_{O 1}+t_{O 2}+t_{O 4}+t_{O 5}+t_{O 6}+t_{O 7}+t_{O 8}$. 
Table 3 represents the details of the allocated tolerance, machining time, process number, and the machine number obtained by Geetha et al. [36]. In this paper, to demonstrate the need to consider the product sequence, the machine idle time cost was calculated for a different product sequence for the allocated tolerance, process number, and the machine number obtained by Geetha et al. [36].The inclusion of the product sequence reduced the machine idle time cost. Thus, the product sequence was included in the present work. Hence, in this paper, for the same process number and machine number for each operation of wheel mounting assembly and the subassembly tolerance, the different tolerance has been distributed among the components for different product sequence, which gives different tolerance cost and machining time.

Figures 3 and 4 present the least machine idle time and the best product sequence with different objectives, with and without considering quality loss costs. The countable savings (i.e., the effectiveness of the proposed work) is shown in Figure 5 where the machine idle time cost obtained with the proposed method is compared with that obtained with the existing method. The results show that more cost savings can be achieved by manufacturing the components in sequence.

\subsection{Implementation of the GA}

The representation of the problem using genes and chromosomes in stage 1 and 2 of the work is presented in Table 4. The basic concepts and working principles of the GA were described by Deb [65]. Table 5 represents the values of the GA parameters assumed in the present work.

Tables 6 and 7 represent the process number, machine number, and subassembly tolerances considered in Geetha et al. [36]. In the proposed method, for each objective function, the tolerance of the components/operations is allocated to satisfy the known subassembly tolerance values in the first stage. For the allocated tolerance values obtained in the first stage, the best product/component sequence is to determine to minimize the machine idle time cost in the second stage. The distribution of a component's tolerance corresponding to the subassembly tolerances, $t_{\mathrm{y} 1}$ and $\mathrm{t}_{\mathrm{y} 2}$, are shown in Figures 6 and 7 respectively. The tolerance cost and machining time of each operation for various objective 
functions are presented in Table 8. The best product/component sequence, operation sequence, total tolerance cost, total machine idle time cost, and total cost are shown in Table 9. Figures 8 and 9 represent the distribution of the components/operation tolerance of $t_{y 1}$ and $t_{y 2}$ while considering the quality loss. The tolerance cost and machining time of an individual operation for different objectives are shown in Figures 10 and 11, together with the quality loss cost. The best product sequence for considering the quality loss cost is tabulated in Table 10.

\section{Results and Discussion}

The total cost comparison of the existing and proposed method is shown in Figure 12. As clear from Figure 12, for all objective functions without considering the quality loss cost, the inclusion of the component/operation sequence results in considerable cost savings in product production. With regard to quality loss costs, considerable cost savings are possible with all the objective functions, other than objective function $\mathrm{Z} 3$, when the component/operation is carried out in sequence. The cost savings are due to the ability to make components with a wider tolerance applying a process with higher manufacturing cost. The total cost is almost equal in objective function $\mathrm{Z} 3$ because only the machine idle time cost is considered an objective function. The component/operation sequence does not have any role in minimizing the total machine idle cost. Thus, considerable savings cannot be made in the total cost value of objective function $\mathrm{Z} 3$.

\section{Conclusion}

Most previous studies of tolerance allocation problems have concentrated on minimizing manufacturing costs, quality loss, or a combination of the two, with scarce attention paid to machining time, an important manufacturing parameter. In this paper, the machining time was considered, along with the manufacturing cost, in optimum tolerance allocation of complex assemblies, thereby representing a more realistic product

development scenario. Alternative machine and process selections with component/operation sequence consideration make this problem cumbersome and complex. 
Therefore, we developed a new methodology, which consists of two stages, and applied a GA to obtain the lowest total cost when manufacturing a product. The results presented in this paper demonstrate that the proposed methodology can reduce tolerance costs and machining time in less computation time.

The proposed method is also suitable for solving two- and three-dimensional problems. As a further extension of this work, the operation sequence, machine sequence, or both could be considered with additional objectives, such as the minimization of mean flow time, makespan, total investment cost of machines, idle time of machines, idle cost of machines, and number of machines required for manufacturing a product.

\section{References}

1. Singh PK, Jain SC, Jain PK (2004a) A genetic algorithm based solution to optimum tolerance synthesis of mechanical assemblies with alternate manufacturing processesbenchmarking with the exhaustive search method using the lagrange multiplier. Proc IMechE, Part B Journal of Engineering Manufacture 218 (B7):765-778.

2. Chase KW, Greenwood WH, Loosli BG, Hauglund LF (1990) Least cost tolerance allocation for mechanical assemblies with automated process selection. Manuf Rev 3(1):49-59.

3. Chen M.S. (1996), Optimizing Tolerance Allocation for Mechanical Components Correlated by Selective Assembly, International Journal of Advanced Manufacturing Technology, 12(5):349-355.

4. Christopher C. Yang and Achuthanaikan V.N. (2003), Optimum Tolerance Design for Complex Assemblies using Hierarchical Interval Constraint Networks, Computers and Industrial Engineering, 45(3):511-543.

5. Cheng KM, Tsai JC (2011), Optimal statistical tolerance allocation of assemblies for minimum manufacturing cost. Applied Mechanics and Materials 52-54:1818-1823.

6. Cheng KM, Tsai JC(2013),Optimal Statistical Tolerance Allocation for Reciprocal Exponential Cost-Tolerance Function, Proceedings of the Institution of Mechanical Engineers, Part B: Journal of Engineering Manufacture, 227(5): 650 - 656.

7. Siva Kumar M., Kannan S.M. and Jayabalan V. (2007), Construction of closed-form equations and graphical representation for optimal tolerance allocation, International Journal of Production Research, 45(6):1449-1468. 
8. Kim CB, Pulat S, Foote B L, Lee D H (1999), Least Cost Tolerance Allocation and Bicriteria Extension, International Journal of Computer Integrated Manufacturing, 12(5):418-426.

9. Gadallah MH (2011), Least sensitive tolerance allocation. International Journal of Quality Engineering and Technology 2(4):344-356.

10. Lee WJ, Woo TC (1989), Optimum selection of discrete tolerances T ASME J Mech Transmissions Autom Des 111:243-251.

11. Feng CXJ, Kusiak A (2000), Robust tolerance synthesis with the design of experiments approach. J Manuf Sci Eng 122(3):520-528.

12. Zhang C, Wang H P (1993), The discrete tolerance optimization problem, Manuf. Rev., 6(1):60-71.

13. Ji S, Li X, Ma Y, Cai H (2000),Optimal tolerance allocation based on fuzzy comprehensive evaluation and genetic algorithm. Int J Adv Manuf Technol 16(7):461468.

14. Sangeet Uttam (2001), Optimal tolerance synthesis for process selection with machine selection. M.S. Thesis, University of Cincinnati.

15. Ming XG, Mak KL (2001), Intelligent approaches to tolerance allocation and manufacturing operations selection in process planning. J Mater Process Technol 117(1-2):75-83.

16. Singh P.K., Jain P.K. and Jain S.C. (2003), Simultaneous Optimal Selection of Design and Manufacturing Tolerances with Different Stack-up Conditions using Genetic Algorithms, International Journal of Production Research, 41(11):2411-2429.

17. Prabhaharan G, Asokan P, Ramesh P, Rajendran S (2004), Genetic algorithm-based optimal tolerance allocation using a least-cost model. Int J Adv Manuf Technol 24(910):647-660.

18. Etienne A, Dantan JY, Qureshi J, Siadat A (2008), Variation management by functional tolerance allocation and manufacturing process selection. Int $J$ Interact Des Manuf 2(4):207-218.

19. Wua F, Dantan JY, Etienne A, Siadat A, Martin P (2009), Improved algorithm for tolerance allocation based on Monte Carlo simulation and discrete optimization. Comput Ind Eng 56:1402-1413.

20. Sivakumar K , Balamurugan C, Ramabalan S, Venkata Raman SB (2009), Optimal concurrent dimensional and geometrical tolerancing based on evolutionary algorithms, 
World Congress on Nature \& Biologically Inspired Computing (NaBIC 2009), 300305.

21. Sivakumar K, Balamurugan C, Ramabalan S (2010), Concurrent multi-objective tolerance allocation of mechanical assemblies considering alternative manufacturing process selection. Int J Adv Manuf Technol 53(5-8):711-732.

22. Sivasubramanian R, Siva Kumar M (2010), Optimum tolerance synthesis with process and machine selection for minimizing manufacturing cost and machining time by using genetic algorithm. Journal of Manufacturing Technology Research 2(1-2):93-108.

23. Chase K.W. and Greenwood W.H. (1988), Design Issues in Mechanical Tolerance Analysis, Manufacturing Review, 1(1):50-59.

24. Spotts M.F. (1978), Dimensioning Stacked Assemblies, Machine Design, 50(9):60-63.

25. Sutherland G.H. and Roth B. (1975), Mechanism Design: Accounting for Manufacturing Tolerance and Costs in Function Generating Problems, ASME Journal of Engineering for Industry, 97:283-286.

26. Speckhart F.H. (1972), Calculation of Tolerance based on a Minimum Cost Approach, ASME Journal of Engineering for Industry, 94(2):447-453.

27. Dong Z., Hu W. and Xue D. (1994), New Production Cost- Tolerance Models for Tolerance Synthesis, ASME Journal of Engineering for Industry, 116(2):199-206.

28. Singh PK, Jain PK, Jain SC (2004), A genetic algorithm based solution to optimal tolerance synthesis of mechanical assemblies with alternative manufacturing processes: focus on complex tolerancing problems. Int J Prod Res 42(24):5185-5215.

29. Ostwald P.F. and Huang J. (1977), A Method for Optimal Tolerance Selection, ASME Journal of Engineering for Industry, 99:558-565.

30. Liu S. G., Jin Q., Liu C. and Xie R.J. (2013), Analytical method for optimal component tolerances based on manufacturing cost and quality loss, Proceedings of the Institution of Mechanical Engineers, Part B: Journal of Engineering Manufacture, 227(10):14841491.

31. Feng CXJ and Kusiak A (1997), Robust Tolerance Design with the Integer Programming Approach, ASME Journal of Manufacturing Science and Engineering, 119(4A): 603-610.

32. Chase KW (1999), Minimum Cost Tolerance Allocation, ADCATS Report No. 99-5, Department of Mech. Engg., Brigham Young University. 
33. Vasseur H., Kurfess T.R. and Cagan J. (1997), Use of a Quality Loss Function to Select Statistical Tolerances, Journal of Manufacturing Science and Engineering, 119(3):410416.

34. Sampath kumar R, Alagumurthi N, Ramesh R (2010), Integrated total cost and Tolerance Optimization with Genetic Algorithm, International Journal of Computational Intelligence Systems, 3(3): 325 - 333.

35. Rao YS (2011) ,Simultaneous tolerance synthesis for manufacturing and quality using evolutionary algorithms. International Journal of Applied Evolutionary Computation (IJAEC) 2(2):1- 20.

36. Geetha K, Ravindran D, Siva Kumar M, Islam M N (2013), Multi-objective optimization for optimum tolerance synthesis with process and machine selection using a genetic algorithm, Int J Adv Manuf Technol (2013) 67:2439-2457.

37. Liu S G, Jin Q (2013), Closed-Form Optimal Tolerance for Minimum Manufacturing Cost and Quality Loss Cost, Advanced Materials Research, 655 - 657: 2084-2087.

38. Wu Z., Elmaraghy W.H. and Elmaraghy H.A. (1988), Evaluation of Cost-Tolerance Algorithms for Design Tolerance Analysis and Synthesis, Manufacturing Review, 1(3): 168-179.

39. Dilplaris SC, Sfantsikopoulos P (2001), Cost-tolerance function: a new approach for cost optimum machining accuracy. Int J Adv Manuf Technol 16(1):32-38.

40. Choi HGR, Park MH, Erik S (2000), Optimal Tolerance Allocation with Loss Functions, Journal of Manufacturing Science and Engineering, 122(3):529-535.

41. Chou CY, Chang CL (2001), Minimum-loss assembly tolerance allocation by considering product degradation and time value of money. Int $\mathrm{J}$ Adv Manuf Technol 17(2):139-146.

42. Ye B, Salustri FA (2003) ,Simultaneous tolerance synthesis for manufacturing and quality. Res Eng Des 14(2):98-106.

43. GopalaKrishnan B, Jaraiedi M, Iskander WH, Ahmad A (2007) ,Tolerance synthesis based on Taguchi philosophy. Int J Ind Syst Eng 2(3):331-326.

44. Jayaprakash G, Sivakumar K, Thilak M (2012), FEA compliant parametric tolerance allocation of mechanical assembly using neural network and differential evolution algorithm. Int J Comput Integr Manuf. 25 (7):636-654.

45. Zhang C. and Wang H.P. (1997), Robust Design of Assembly and Machining Tolerance Allocations, IIE Transactions, 30(1):17-29. 
46. Singh PK, Jain SC, Jain PK (2005), Advanced optimal tolerance design of mechanical assemblies with interrelated dimension chains and process precision limits. Comput Ind $56(2): 179-194$.

47. Sivakumar K, Balamurugan C, Ramabalan S (2012), Evolutionary multi-objective concurrent maximisation of process tolerances, International Journal of Production Research, 50(12): 3172-3191.

48. Dong Z., and Andres S (1990), Automatic Optimal Tolerance Design for Related Dimension Chains, ASME Manufacturing Review, 3(4):262-271.

49. Jeang A, Chang CL (2002), Combined robust parameter and tolerance design using orthogonal arrays. Int J Adv Manuf Technol 19 (6):442-447.

50. Rao S, Wu W (2005), Optimum tolerance allocation in mechanical assemblies using an interval method. Eng Optim 37(3):237-257.

51. Savage GJ, Tong D, Carr SM (2005), Optimal Mean and Tolerance Allocation Using Conformance-based Design, Quality and Reliability Engineering International, 22(4): 445-472.

52. Huang YM, Shiau CS(2006),Optimal Tolerance Allocation for a Sliding Vane Compressor, Journal of Mechanical Design, 128(1): 98-107.

53. Li Z, Kokkolaras M, Izquierdo L.E., Papalambros P.Y., Hu S.J., (2008), Multiobjective Optimization for Integrated Tolerance Allocation and Fixture Layout Design in Multistation Assembly, Journal of Manufacturing Science and Engineering, 130(4): 5011- 5016.

54. Janakiraman V, Saravanan R (2010), Concurrent optimization of machining process parameters and tolerance allocation. Int J Adv Manuf Technol 51(1-4):357-369.

55. Hung T.C., Chan K.Y., (2013), Multi-objective design and tolerance allocation for single and multi-level system, Journal of Intelligent Manufacturing 24 (3):559-573.

56. Ahmad Barari (2013), Tolerance allocation Based on the Minimum Deformation Zone of Finite Element Structural Frame Analysis, Computer- Aided Design \& Applications, 10(4): 629- 641.

57. Prabhaharan G, Asokan P, Rajendran S (2005), Sensitivity-based conceptual design and tolerance allocation using the continuous ants colony algorithm (CACO). Int $\mathrm{J}$ Adv Manuf Technol 25(5-6):516-526.

58. Rajesh S, Toshihiro T, Koji I, Nobuhiro S (2008), A study on integration of process planning and scheduling system for holonic manufacturing with modification of process 
plans, International Journal of Manufacturing Technology and Management, 14(3/4):359-378.

59. Xinyu Li, Liang Gao, Xinyu Shao, Chaoyong Zhang, Cuiyu Wang (2010), Mathematical modeling and evolutionary algorithm-based approach for integrated process planning and scheduling, Computers \& Operations Research, 37(4): 656-667.

60. Li W D, Gao L, Li X Y, Guo Y (2008), Game Theory-Based Cooperation of Process Planning and Scheduling. In: Proceeding of CSCWD, pp 841-845. IEEE Press, New York.

61. Guo Y W, Li W D, Mileham A R, Owen G W(2009), Applications of particle swarm and optimization in integrated process planning and scheduling. Robotics and Computer-Integrated Manufacturing, 25: 280-288.

62. Hengyun Z, Wenhua Y,Guangxia B(2009), A particle swarm optimization for integrated process planning and scheduling, International Conference on ComputerAided Industrial Design \& Conceptual Design, CAID \& CD 2009. 1070 - 1074.

63. Xinyu Li, Liang Gao, Guohui Zhang, Chaoyong Zhang, Xinyu Shao (2008), A Genetic Algorithm for Integration of Process Planning and Scheduling Problem, C. Xiong et al. (Eds.): ICIRA 2008, Part II, LNAI 5315, pp 495-502.

64. Xinyu Li, Xinyu Shao, Liang Gao, Weirong Qian (2010), An effective hybrid algorithm for integrated process planning and scheduling, International Journal of Production Economics, 126(2): 289-298.

65. Deb K (1995) Optimization for engineering design: algorithm and examples PrenticeHall, India.

66. Zhang C, Wang H P (1993a), Integrated Tolerance Optimization with Simulated Annealing, International Journal of Advanced Manufacturing Technology, 8:167-174.

67. Carfagni M, Governi L, Fhiesi F (2001), Development of a method for automatic tolerance allocation, Proceeding of the XII ADM International Conference, Italy, D120-D1-27.

\section{List of Tables}

Table 1: Dimension and tolerance symbol of wheel-mounting assembly

Table 2: Cost and time function constants for wheel-mounting assembly

Table 3: Details of allocated tolerance in Geetha et al. [23]

Table 4: Genetic algorithm (GA) representation of the problem 
Table 5: Parameter values in the genetic algorithm (GA)

Table 6: Process and machine number for different operations without $C_{Q L}$

Table 7: Process and machine number for different operations with $C_{Q L}$

Table 8: Tolerance cost and machining time of the proposed method without $C_{Q L}$

Table 9: The best product sequence and its total cost without $C_{Q L}$

Table 10: The best product sequence and its total cost with $C_{Q L}$

\section{List of Figures}

Fig. 1: Scheme of the proposed method

Fig. 2: Wheel mounting assembly

Fig. 3: Machine idle time for the best product sequence of each objective function without $C_{Q L}$

Fig. 4: Machine idle time for the best product sequence of each objective function with $C_{Q L}$

Fig. 5: Comparison of the total machine idle time cost

Fig. 6: Distribution of component's tolerance in each operation for $t_{y l}$ without $C_{Q L}$

Fig. 7: Distribution of component's tolerance in each operation for $t_{y 2}$ without $C_{Q L}$

Fig. 8: Distribution of component's tolerance in each operation for $t_{y l}$ with $C_{Q L}$

Fig. 9: Distribution of component's tolerance in each operation for $t_{y 2}$ with $C_{Q L}$

Fig. 10: Machining time of each operation with $C_{Q L}$

Fig. 11: Tolerance cost of each operation with $C_{Q L}$

Fig. 12: Comparison of the total cost of the existing and proposed method 
Table 1: Dimension and tolerance symbol of wheel mounting assembly

\begin{tabular}{|c|c|c|c|c|}
\hline $\begin{array}{l}\text { Name of the } \\
\text { Components } \\
\text { /Particulars }\end{array}$ & $\begin{array}{l}\text { Dimension } \\
\text { No. }\end{array}$ & $\begin{array}{l}\text { Operation / } \\
\text { Sub stage No. }\end{array}$ & $\begin{array}{l}\text { Tolerance } \\
\text { symbol }\end{array}$ & Tolerance stack-up \\
\hline Left side support & $\mathrm{X} 1$ & $\mathrm{O} 1$ and $\mathrm{O} 2$ & $t_{X 1}$ & $\mathrm{t}_{\mathrm{O} 1}+\mathrm{t}_{\mathrm{O} 2}$ \\
\hline Wheel & $\mathrm{X} 4$ & $\mathrm{O} 3$ & $t_{X 4}$ & $t_{03}$ \\
\hline Right side support & $\mathrm{X} 3$ & $\mathrm{O} 4$ and $\mathrm{O} 5$ & $t_{x 3}$ & $\mathrm{t}_{\mathrm{O} 4}+\mathrm{t}_{\mathrm{O} 5}$ \\
\hline Shaft & $\mathrm{X} 5$ & O6 & $t_{X 5}$ & $t_{06}$ \\
\hline Spacer & $\mathrm{X} 2$ & $\mathrm{O} 7$ and $\mathrm{O} 8$ & $t_{X 2}$ & $t_{07}+t_{08}$ \\
\hline Critical dimension 1 & Y1 & & $t_{Y 1}$ & $\mathrm{t}_{\mathrm{O} 3}+\mathrm{t}_{\mathrm{O} 7}+\mathrm{t}_{\mathrm{O} 8}$ \\
\hline Critical dimension 2 & Y2 & & $t_{\mathrm{Y} 2}$ & $\begin{array}{l}\mathrm{t}_{\mathrm{O} 1}+\mathrm{t}_{\mathrm{O} 2}+\mathrm{t}_{\mathrm{O} 4}+\mathrm{t}_{\mathrm{O} 5}+\mathrm{t}_{\mathrm{O} 6} \\
+\mathrm{t}_{\mathrm{O} 7}+\mathrm{t}_{\mathrm{O} 8}\end{array}$ \\
\hline
\end{tabular}

Table 2: Cost and Time Function Constants for WMA

\begin{tabular}{|c|c|c|c|c|c|c|c|c|c|c|}
\hline \multirow{2}{*}{$\begin{array}{l}\text { Process } \\
\text { number }\end{array}$} & \multicolumn{2}{|c|}{$\begin{array}{c}\text { Cost } \\
\text { function } \\
\text { constant }\end{array}$} & \multicolumn{2}{|c|}{$\begin{array}{c}\text { Time } \\
\text { function } \\
\text { constant }\end{array}$} & \multicolumn{2}{|c|}{$\begin{array}{l}\text { Process capability } \\
\text { limits in mm }\end{array}$} & \multicolumn{4}{|c|}{$\begin{array}{c}\text { Cost and Time manipulating Factor } \\
\text { Machine Numbers }\end{array}$} \\
\hline & ai & $\mathrm{bi}$ & $\mathrm{Xi}$ & $\mathrm{Yi}$ & $\mathrm{t}_{\min }$ & $\mathrm{t}_{\max }$ & M1 & M2 & M3 & M4 \\
\hline P1 & 1.4 & 0.24 & 2 & 0.4 & 0.01 & 0.08 & 0.8 & 0 & 1.15 & 0 \\
\hline P2 & 1.5 & 0.22 & 5 & 0.2 & 0.03 & 0.09 & 0 & 0.85 & 1 & 0 \\
\hline P3 & 0.9 & 0.18 & 3 & 0.8 & 0.02 & 0.07 & 0.85 & 0 & 0.9 & 1.02 \\
\hline $\mathrm{P} 4$ & 2.5 & 0.23 & 4.5 & 0.5 & 0.03 & 0.13 & 0 & 1.11 & 0.95 & 0 \\
\hline P5 & 1.9 & 0.15 & 3 & 0.2 & 0.009 & 0.1 & 1.08 & 1.01 & 0 & 0.8 \\
\hline
\end{tabular}

Table 3: Details of allocated tolerance in Geetha et al. [23]

\begin{tabular}{|c|c|c|c|c|c|c|c|c|c|}
\hline \multirow[t]{2}{*}{ Objective } & \multicolumn{5}{|c|}{ As per Table 10 in Geetha et al. } & \multicolumn{4}{|c|}{ As per Table 12 in Geethaet. al. } \\
\hline & $\begin{array}{l}\dot{0} \\
\dot{z} \\
\dot{0}\end{array}$ & $\dot{z}_{0}^{\dot{z}}$ & $\begin{array}{l}\dot{0} \\
\dot{z} \\
\dot{\Sigma}\end{array}$ & - & $\dot{E}$ & 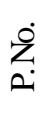 & $\begin{array}{l}\dot{0} \\
\dot{Z} \\
\dot{\Sigma}\end{array}$ & 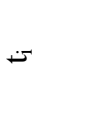 & $\vec{E}$ \\
\hline \multirow[t]{8}{*}{$\mathrm{Z1}$} & $\mathrm{O} 1$ & 4 & 2 & 0.077843 & 12.12 & 2 & 2 & 0.0534 & 7.43 \\
\hline & $\mathrm{O} 2$ & 1 & 1 & 0.070941 & 6.11 & 5 & 1 & 0.0532 & 7.30 \\
\hline & $\mathrm{O} 3$ & 2 & 2 & 0.062235 & 6.98 & 2 & 3 & 0.0526 & 8.80 \\
\hline & $\mathrm{O} 4$ & 5 & 4 & 0.035051 & 6.96 & 3 & 3 & 0.0657 & 13.65 \\
\hline & O5 & 1 & 1 & 0.038 & 10.02 & 1 & 1 & 0.0427 & 9.09 \\
\hline & O6 & 2 & 3 & 0.081529 & 7.45 & 5 & 4 & 0.0581 & 5.16 \\
\hline & O7 & 3 & 4 & 0.048824 & 19.77 & 3 & 1 & 0.0659 & 12.87 \\
\hline & O8 & 2 & 3 & 0.066706 & 8.00 & 1 & 1 & 0.0748 & 5.88 \\
\hline \multirow[t]{3}{*}{$\overline{\mathrm{Z} 2}$} & O1 & 2 & 3 & 0.083176 & 7.40 & 1 & 1 & 0.0376 & 10.12 \\
\hline & $\mathrm{O} 2$ & 1 & 1 & 0.024275 & 14.78 & 5 & 4 & 0.0353 & 6.94 \\
\hline & $\mathrm{O} 3$ & 2 & 2 & 0.071176 & 6.64 & 2 & 2 & 0.0369 & 8.85 \\
\hline
\end{tabular}




\begin{tabular}{|c|c|c|c|c|c|c|c|c|c|}
\hline & $\mathrm{O} 4$ & 5 & 4 & 0.081443 & 4.36 & 5 & 2 & 0.0737 & 5.77 \\
\hline & O5 & 1 & 1 & 0.056392 & 7.27 & 1 & 1 & 0.062 & 6.76 \\
\hline & O6 & 2 & 3 & 0.063176 & 8.17 & 5 & 4 & 0.0748 & 4.54 \\
\hline & $\mathrm{O} 7$ & 3 & 4 & 0.064706 & 15.67 & 4 & 2 & 0.0511 & 15.85 \\
\hline & O8 & 2 & 3 & 0.031647 & 11.32 & 2 & 3 & 0.0785 & 7.55 \\
\hline \multirow[t]{8}{*}{ Z3 } & $\mathrm{O} 1$ & 4 & 3 & 0.064118 & 11.68 & 4 & 3 & 0.1005 & 9.00 \\
\hline & $\mathrm{O} 2$ & 1 & 1 & 0.047333 & 8.36 & 1 & 1 & 0.03 & 12.25 \\
\hline & $\mathrm{O} 3$ & 2 & 2 & 0.079412 & 6.39 & 2 & 3 & 0.0687 & 7.91 \\
\hline & $\mathrm{O} 4$ & 5 & 4 & 0.048969 & 5.67 & 3 & 4 & 0.0317 & 28.78 \\
\hline & O5 & 1 & 1 & 0.048706 & 8.17 & 4 & 2 & 0.0544 & 15.20 \\
\hline & O6 & 2 & 3 & 0.045059 & 9.44 & 5 & 1 & 0.0167 & 16.20 \\
\hline & $\mathrm{O} 7$ & 3 & 4 & 0.062941 & 16.02 & 3 & 3 & 0.066 & 13.61 \\
\hline & $\mathrm{O} 8$ & 2 & 3 & 0.060824 & 8.29 & 2 & 2 & 0.0422 & 8.28 \\
\hline \multirow[t]{8}{*}{$\mathrm{Z1Z2}$} & $\mathrm{O} 1$ & 1 & 1 & 0.060784 & 6.86 & 2 & 2 & 0.0392 & 8.58 \\
\hline & $\mathrm{O} 2$ & 1 & 1 & 0.061882 & 6.77 & 3 & 4 & 0.0697 & 14.77 \\
\hline & $\mathrm{O} 3$ & 2 & 2 & 0.039412 & 8.56 & 2 & 3 & 0.0415 & 9.81 \\
\hline & $\mathrm{O} 4$ & 5 & 4 & 0.041831 & 6.22 & 5 & 4 & 0.0393 & 6.48 \\
\hline & O5 & 1 & 1 & 0.055569 & 7.36 & 1 & 1 & 0.0579 & 7.12 \\
\hline & O6 & 2 & 3 & 0.070471 & 7.84 & 5 & 4 & 0.0967 & 4.05 \\
\hline & $\mathrm{O} 7$ & 3 & 4 & 0.062745 & 16.07 & 3 & 1 & 0.0525 & 15.51 \\
\hline & O8 & 2 & 3 & 0.056824 & 8.52 & 2 & 2 & 0.047 & 7.87 \\
\hline \multirow[t]{8}{*}{ Z1Z3 } & O1 & 1 & 1 & 0.064078 & 6.59 & 1 & 3 & 0.0679 & 9.08 \\
\hline & $\mathrm{O} 2$ & 1 & 1 & 0.05502 & 7.42 & 3 & 3 & 0.0364 & 22.48 \\
\hline & $\mathrm{O} 3$ & 2 & 2 & 0.075176 & 6.51 & 4 & 2 & 0.0836 & 11.64 \\
\hline & $\mathrm{O} 4$ & 5 & 4 & 0.050753 & 5.55 & 3 & 1 & 0.0642 & 13.14 \\
\hline & O5 & 1 & 1 & 0.028667 & 12.76 & 1 & 1 & 0.056 & 7.32 \\
\hline & O6 & 2 & 3 & 0.035176 & 10.69 & 2 & 2 & 0.0447 & 8.05 \\
\hline & O7 & 3 & 4 & 0.048627 & 19.84 & 3 & 4 & 0.0298 & 30.41 \\
\hline & O8 & 2 & 3 & 0.075882 & 7.64 & 2 & 2 & 0.0734 & 6.57 \\
\hline \multirow[t]{8}{*}{ Z2Z3 } & $\mathrm{O} 1$ & 2 & 3 & 0.039176 & 10.11 & 2 & 3 & 0.0485 & 9.12 \\
\hline & $\mathrm{O} 2$ & 1 & 1 & 0.072314 & 6.03 & 5 & 1 & 0.0779 & 6.01 \\
\hline & $\mathrm{O} 3$ & 2 & 2 & 0.045294 & 8.00 & 2 & 3 & 0.0772 & 7.59 \\
\hline & $\mathrm{O} 4$ & 5 & 4 & 0.041475 & 6.26 & 3 & 4 & 0.034 & 27.09 \\
\hline & O5 & 1 & 1 & 0.061333 & 6.82 & 1 & 3 & 0.0691 & 8.95 \\
\hline & O6 & 2 & 3 & 0.045059 & 9.44 & 5 & 1 & 0.0443 & 8.11 \\
\hline & O7 & 3 & 4 & 0.069412 & 14.82 & 4 & 2 & 0.0347 & 21.00 \\
\hline & O8 & 2 & 3 & 0.05 & 9.00 & 2 & 2 & 0.0732 & 6.57 \\
\hline \multirow[t]{8}{*}{ Z1Z2Z3 } & $\mathrm{O} 1$ & 1 & 3 & 0.057765 & 10.26 & 1 & 3 & 0.0396 & 13.93 \\
\hline & $\mathrm{O} 2$ & 1 & 1 & 0.046235 & 8.52 & 5 & 1 & 0.054 & 7.24 \\
\hline & $\mathrm{O} 3$ & 2 & 2 & 0.058941 & 7.13 & 2 & 3 & 0.0537 & 8.73 \\
\hline & $\mathrm{O} 4$ & 5 & 4 & 0.075376 & 4.52 & 5 & 2 & 0.0615 & 6.31 \\
\hline & O5 & 1 & 1 & 0.040745 & 9.45 & 1 & 1 & 0.0505 & 7.94 \\
\hline & O6 & 2 & 3 & 0.047882 & 9.18 & 5 & 1 & 0.0506 & 7.51 \\
\hline & $\mathrm{O} 7$ & 3 & 4 & 0.065686 & 15.48 & 3 & 4 & 0.05 & 19.37 \\
\hline & O8 & 2 & 3 & 0.070706 & 7.83 & 2 & 2 & 0.0619 & 7.00 \\
\hline
\end{tabular}


Table 4: GA Representation of the Problem

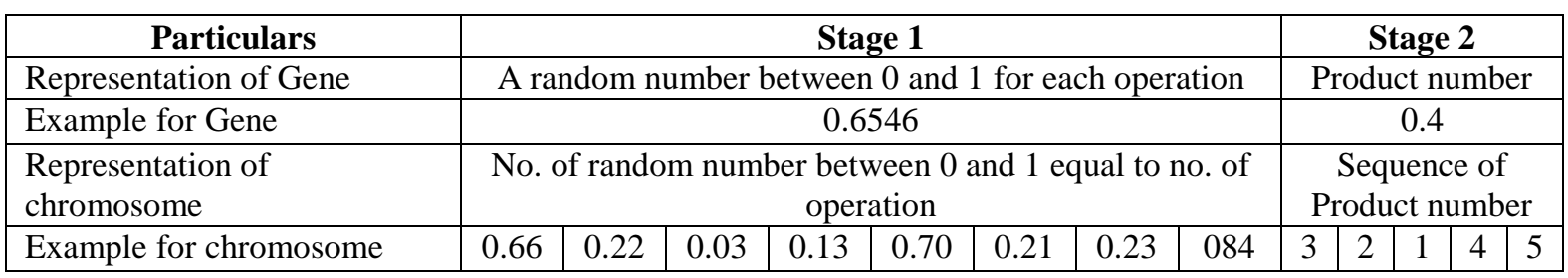

Table 5: GA Parameter's Value

\begin{tabular}{|c|c|c|}
\hline Particulars & Stage 1 & Stage 2 \\
\hline Population Size & 40 & 20 \\
\hline Selection Process & \multicolumn{2}{|c|}{ Roulette wheel selection } \\
\hline Cross over probability & 0.45 & 0.4 \\
\hline Cross over method & \multicolumn{2}{|c|}{ Single point } \\
\hline Mutation probability & 0.03 & 0.025 \\
\hline Replacement strategy & \multicolumn{2}{|c|}{ Complete replacement } \\
\hline Stopping criteria & $\begin{array}{l}1000 \text { iterations or no change in } 50 \\
\text { consecutive iteration's fitness value }\end{array}$ & $\begin{array}{l}500 \text { Iteration or no change in } 50 \\
\text { consecutive iteration's fitness value }\end{array}$ \\
\hline
\end{tabular}

Table 6: Process and machine number for different operation without $C_{Q L}$

\begin{tabular}{|c|c|c|c|c|c|c|c|c|c|c|c|c|c|c|c|c|c|c|}
\hline \multirow{2}{*}{$\begin{array}{l}\text { Objective } \\
\text { function }\end{array}$} & \multicolumn{2}{|c|}{01} & \multicolumn{2}{|c|}{02} & \multicolumn{2}{|c|}{$\mathrm{O} 3$} & \multicolumn{2}{|c|}{04} & \multicolumn{2}{|c|}{05} & \multicolumn{2}{|c|}{06} & \multicolumn{2}{|c|}{07} & \multicolumn{2}{|c|}{08} & \multirow[b]{2}{*}{ Y1 } & \multirow[b]{2}{*}{ Y2 } \\
\hline & ن & 家 & $\dot{a}$ & $\begin{array}{l}\dot{z} \\
\dot{z}\end{array}$ & $\dot{z}$ & $\begin{array}{l}\dot{z} \\
\dot{z}\end{array}$ & i & $\begin{array}{l}\dot{z} \\
\dot{z}\end{array}$ & $\dot{z}$ & $\stackrel{\dot{z}}{\dot{z}}$ & 宽 & 家 & $\dot{z}$ & $\stackrel{\circ}{\sum_{z}}$ & $\dot{\mathrm{z}}$ & $\begin{array}{l}\dot{z} \\
\dot{\Sigma}\end{array}$ & & \\
\hline $\mathrm{Z1}$ & 4 & 2 & 1 & 1 & 2 & 2 & 5 & 4 & 1 & 1 & 2 & 3 & 3 & 4 & 2 & 3 & 0.177765 & 0.418894 \\
\hline $\mathrm{Z} 2$ & 2 & 3 & 1 & 1 & 2 & 2 & 5 & 4 & 1 & 1 & 2 & 3 & 3 & 4 & 2 & 3 & 0.167529 & 0.404816 \\
\hline $\mathrm{Z3}$ & 4 & 3 & 1 & 1 & 2 & 2 & 5 & 4 & 1 & 1 & 2 & 3 & 3 & 4 & 2 & 3 & 0.203176 & 0.377949 \\
\hline Z1Z2 & 1 & 1 & 1 & 1 & 2 & 2 & 5 & 4 & 1 & 1 & 2 & 3 & 3 & 4 & 2 & 3 & 0.15898 & 0.410106 \\
\hline Z1Z3 & 1 & 1 & 1 & 1 & 2 & 2 & 5 & 4 & 1 & 1 & 2 & 3 & 3 & 4 & 2 & 3 & 0.199686 & 0.358204 \\
\hline Z2Z3 & 2 & 3 & 1 & 1 & 2 & 2 & 5 & 4 & 1 & 1 & 2 & 3 & 3 & 4 & 2 & 3 & 0.164706 & 0.378769 \\
\hline Z1Z2Z3 & 1 & 3 & 1 & 1 & 2 & 2 & 5 & 4 & 1 & 1 & 2 & 3 & 3 & 4 & 2 & 3 & 0.195333 & 0.404396 \\
\hline
\end{tabular}


Table 7: Process and machine number for different operation with $C_{Q L}$

\begin{tabular}{|c|c|c|c|c|c|c|c|c|c|c|c|c|c|c|c|c|c|c|c|}
\hline \multirow{2}{*}{$\begin{array}{l}\text { Objective } \\
\text { function }\end{array}$} & \multicolumn{2}{|c|}{01} & \multicolumn{2}{|c|}{$\mathrm{O} 2$} & \multicolumn{2}{|c|}{$\mathrm{O} 3$} & \multicolumn{2}{|c|}{$\mathrm{O} 4$} & \multicolumn{2}{|c|}{05} & \multicolumn{2}{|c|}{06} & \multicolumn{2}{|c|}{07} & \multicolumn{2}{|c|}{08} & \multirow[b]{2}{*}{ Y1 } & \multirow[b]{2}{*}{ Y2 } & \multirow[b]{2}{*}{$\mathrm{C}_{\mathrm{QL}}$} \\
\hline & Z & 官 & $\dot{z}_{\mathrm{a}}$ & $\stackrel{\dot{0}}{\dot{z}_{z}}$ & $\stackrel{\circ}{\circ}$ & $\stackrel{\dot{0}}{\dot{z}}$ & $\stackrel{\circ}{\circ}$ & ż & $\dot{2}$ & $\stackrel{\dot{0}}{\dot{z}}$ & $\dot{z}$ & $\dot{o}_{\dot{z}}$ & $\dot{2}$ & $\stackrel{\dot{0}}{\dot{z}}$ & $\dot{\mathrm{Z}}$ & 官 & & & \\
\hline $\mathrm{Z} 1$ & 2 & 2 & 5 & 1 & 2 & 3 & 3 & 3 & 1 & 1 & 5 & 4 & 3 & 1 & 1 & 1 & 0.19322 & 0.41379 & 0.68 \\
\hline $\mathrm{Z} 2$ & 1 & 1 & 5 & 4 & 2 & 2 & 5 & 2 & 1 & 1 & 5 & 4 & 4 & 2 & 2 & 3 & 0.16659 & 0.41303 & 4.33 \\
\hline $\mathrm{Z3}$ & 4 & 3 & 1 & 1 & 2 & 3 & 3 & 4 & 4 & 2 & 5 & 1 & 3 & 3 & 2 & 2 & 0.17686 & 0.34145 & 9.49 \\
\hline $\mathrm{Z1Z2}$ & 2 & 2 & 3 & 4 & 2 & 3 & 5 & 4 & 1 & 1 & 5 & 4 & 3 & 1 & 2 & 2 & 0.14102 & 0.40225 & 11.15 \\
\hline Z1Z3 & 1 & 3 & 3 & 3 & 4 & 2 & 3 & 1 & 1 & 1 & 2 & 2 & 3 & 4 & 2 & 2 & 0.18677 & 0.37233 & 3.8 \\
\hline Z2Z3 & 2 & 3 & 5 & 1 & 2 & 3 & 3 & 4 & 1 & 3 & 5 & 1 & 4 & 2 & 2 & 2 & 0.18500 & 0.38170 & 3.08 \\
\hline Z1Z2Z3 & 1 & 3 & 5 & 1 & 2 & 3 & 5 & 2 & 1 & 1 & 5 & 1 & 3 & 4 & 2 & 2 & 0.16554 & 0.36808 & 7.54 \\
\hline
\end{tabular}

Table 8: Tolerance cost and machining time of proposed method without $C_{Q L}$

\begin{tabular}{|c|c|c|c|c|c|c|c|c|c|c|c|c|c|c|}
\hline \multirow[b]{2}{*}{ O.No. } & \multicolumn{2}{|c|}{$\mathrm{Z1}$} & \multicolumn{2}{|c|}{$\mathrm{Z} 2$} & \multicolumn{2}{|c|}{$\mathrm{Z} 3$} & \multicolumn{2}{|c|}{ Z1Z2 } & \multicolumn{2}{|c|}{$\mathrm{Z1Z3}$} & \multicolumn{2}{|c|}{ Z2Z3 } & \multicolumn{2}{|c|}{ Z!Z2Z3 } \\
\hline & $\mathrm{TC}_{\mathrm{i}}$ & $\mathrm{MT}_{\mathrm{i}}$ & $\mathrm{TC}_{\mathrm{i}}$ & $\mathrm{MT}_{\mathrm{i}}$ & $\mathrm{TC}_{\mathrm{i}}$ & $\mathrm{MT}_{\mathrm{i}}$ & $\mathrm{TC}_{\mathrm{i}}$ & $\mathrm{MT}_{\mathrm{i}}$ & $\mathrm{TC}_{\mathrm{i}}$ & $\mathrm{MT}_{\mathrm{i}}$ & $\mathrm{TC}_{\mathrm{i}}$ & $\mathrm{MT}_{\mathrm{i}}$ & $\mathrm{TC}_{\mathrm{i}}$ & $\mathrm{MT}_{\mathrm{i}}$ \\
\hline O1 & 4.78 & 9.35 & 7.96 & 10.87 & 6.12 & 12.42 & 9.36 & 15.33 & 8.15 & 13.31 & 6.31 & 9.37 & 7.97 & 12.89 \\
\hline $\mathrm{O} 2$ & 6.67 & 10.85 & 3.75 & 5.99 & 6.22 & 10.09 & 3.77 & 6.02 & 3.94 & 6.29 & 4.19 & 6.71 & 4.43 & 7.12 \\
\hline O3 & 3.75 & 6.5 & 4.41 & 7.1 & 3.35 & 6.14 & 6.38 & 8.89 & 3.35 & 6.14 & 4.56 & 7.23 & 3.35 & 6.14 \\
\hline O4 & 2.79 & 4.1 & 2.93 & 4.28 & 2.84 & 4.16 & 2.84 & 4.16 & 2.91 & 4.25 & 2.84 & 4.15 & 2.73 & 4.01 \\
\hline O5 & 7.52 & 12.27 & 4.59 & 7.39 & 6.05 & 9.82 & 3.92 & 6.26 & 6.39 & 10.38 & 6.61 & 10.75 & 6.38 & 10.37 \\
\hline O6 & 8.76 & 11.6 & 5.95 & 9.05 & 7.15 & 10.13 & 8.3 & 11.18 & 8.82 & 11.66 & 7.53 & 10.48 & 5.05 & 8.23 \\
\hline O7 & 3.58 & 14.87 & 3.61 & 15.02 & 4.25 & 17.87 & 3.59 & 14.95 & 3.61 & 15 & 3.63 & 15.12 & 4.07 & 17.07 \\
\hline 08 & 8.11 & 11.01 & 7.05 & 10.05 & 5.29 & 8.44 & 5.6 & 8.72 & 6.82 & 9.84 & 6.99 & 9.99 & 6.17 & 9.25 \\
\hline
\end{tabular}

Table 9: The best product sequence and its total cost without $C_{Q L}$

\begin{tabular}{lcccrrr}
\hline Obj. No. & P.Seq & O.Seq & TTC & \multicolumn{1}{c}{ ITC } & \multicolumn{1}{c}{ TLC } \\
\hline Z1 & 14523 & 12367845 & 45.97 & 76.03 & 122.00 \\
Z2 & 31452 & 45123678 & 40.25 & 23.1 & 63.35 \\
Z3 & 31452 & 45123678 & 41.27 & 22.46 & 63.73 \\
Z1Z2 & 14523 & 12367845 & 43.75 & 29.37 & 73.12 \\
Z1Z3 & 14523 & 12367845 & 43.98 & 26.1 & 70.08 \\
Z2Z3 & 31452 & 45123678 & 42.65 & 22.43 & 65.08 \\
Z1Z2Z3 & 31452 & 45123678 & 40.16 & 21.66 & 61.82 \\
\hline
\end{tabular}

Obj. No. - Objective function number; P.Seq. - Product sequence; O.Seq. - Operation sequence;

TTC - Total tolerance cost in \$; ITC - Total machine idle time cost in \$; TLC - Total cost in \$ 
Table 10: The best product sequence and its total cost with $C_{Q L}$

\begin{tabular}{lcccccr}
\hline Obj. No. & P.Seq & O.Seq & TTC & TMIDC & C $_{\text {QL }}$ & TLC \\
\hline Z1 & 21345 & 78124536 & 32.80 & 0 & 0.68 & 33.5 \\
Z2 & 51324 & 61245783 & 44.11 & 123.16 & 4.33 & 172 \\
Z3 & 35124 & 45612783 & 45.52 & 68.03 & 9.49 & 123.04 \\
Z1Z2 & 34512 & 45361278 & 39.29 & 83.46 & 11.15 & 134 \\
Z1Z3 & 13452 & 12453678 & 39.00 & 0 & 3.8 & 42.8 \\
Z2Z3 & 51342 & 61245378 & 52.23 & 0 & 3.08 & 55.3 \\
Z1Z2Z3 & 51342 & 61245378 & 45.83 & 7.41 & 7.54 & 60.8 \\
\hline
\end{tabular}


Fig. 1: Scheme of proposed method

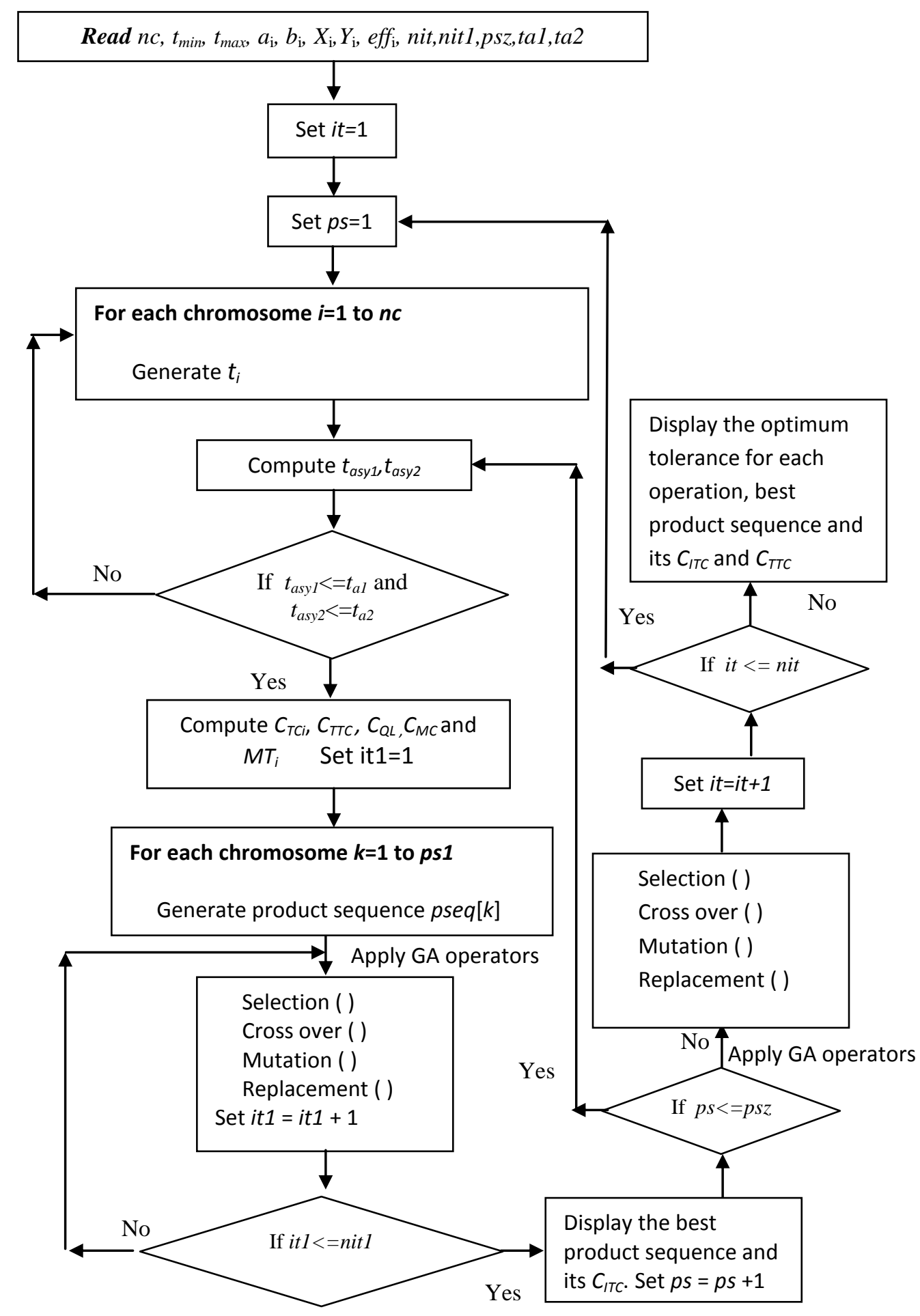


Fig. 2: Wheel mounting assembly

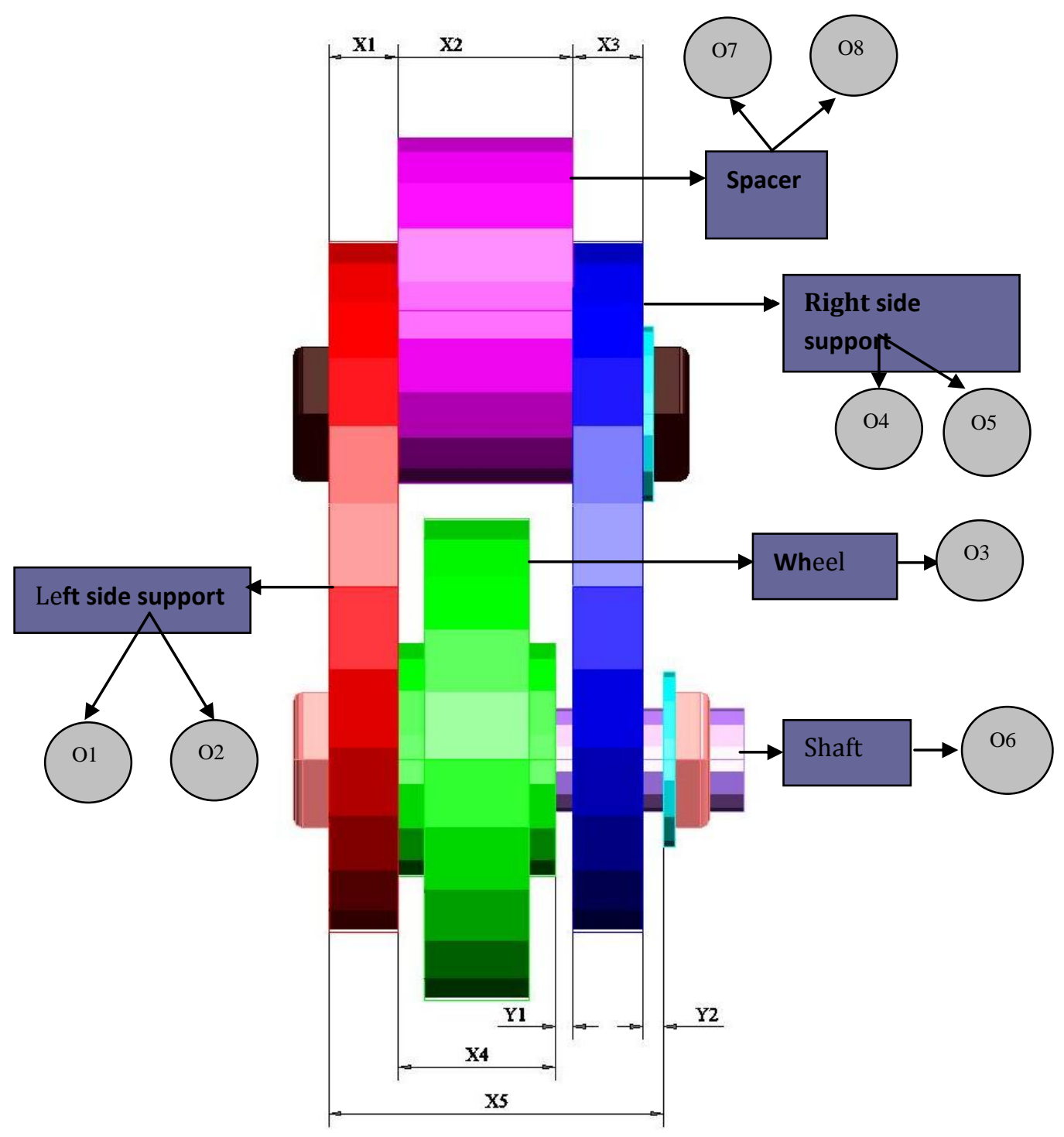


Fig. 3: Machine idle time for the best product sequence of each objective function without $C_{Q L}$

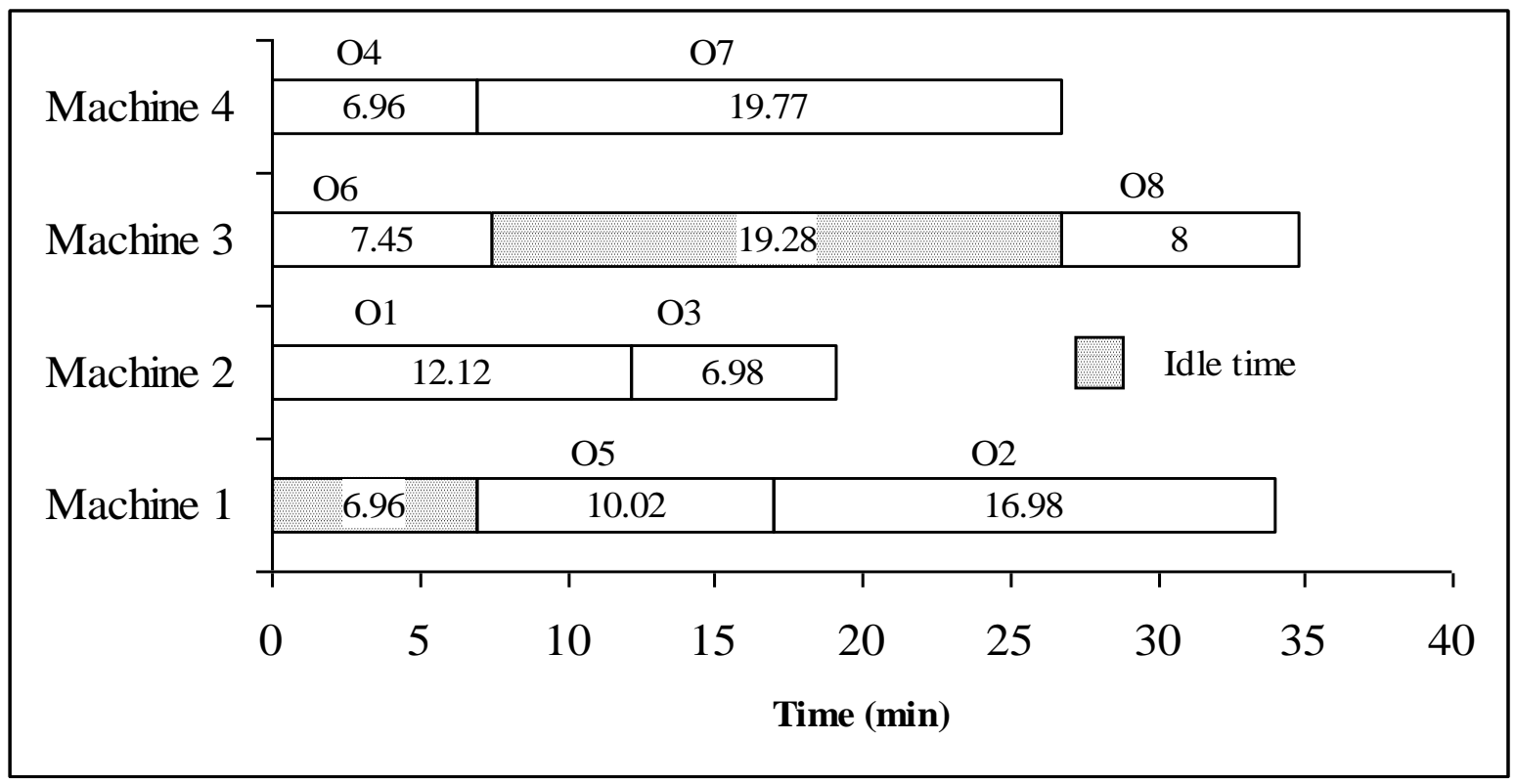

(a) Z1 without $\mathrm{C}_{\mathrm{QL}}$ (Best product sequence $\mathrm{X} 3 \mathrm{X} 1 \mathrm{X} 4 \mathrm{X} 5 \mathrm{X} 2$ )

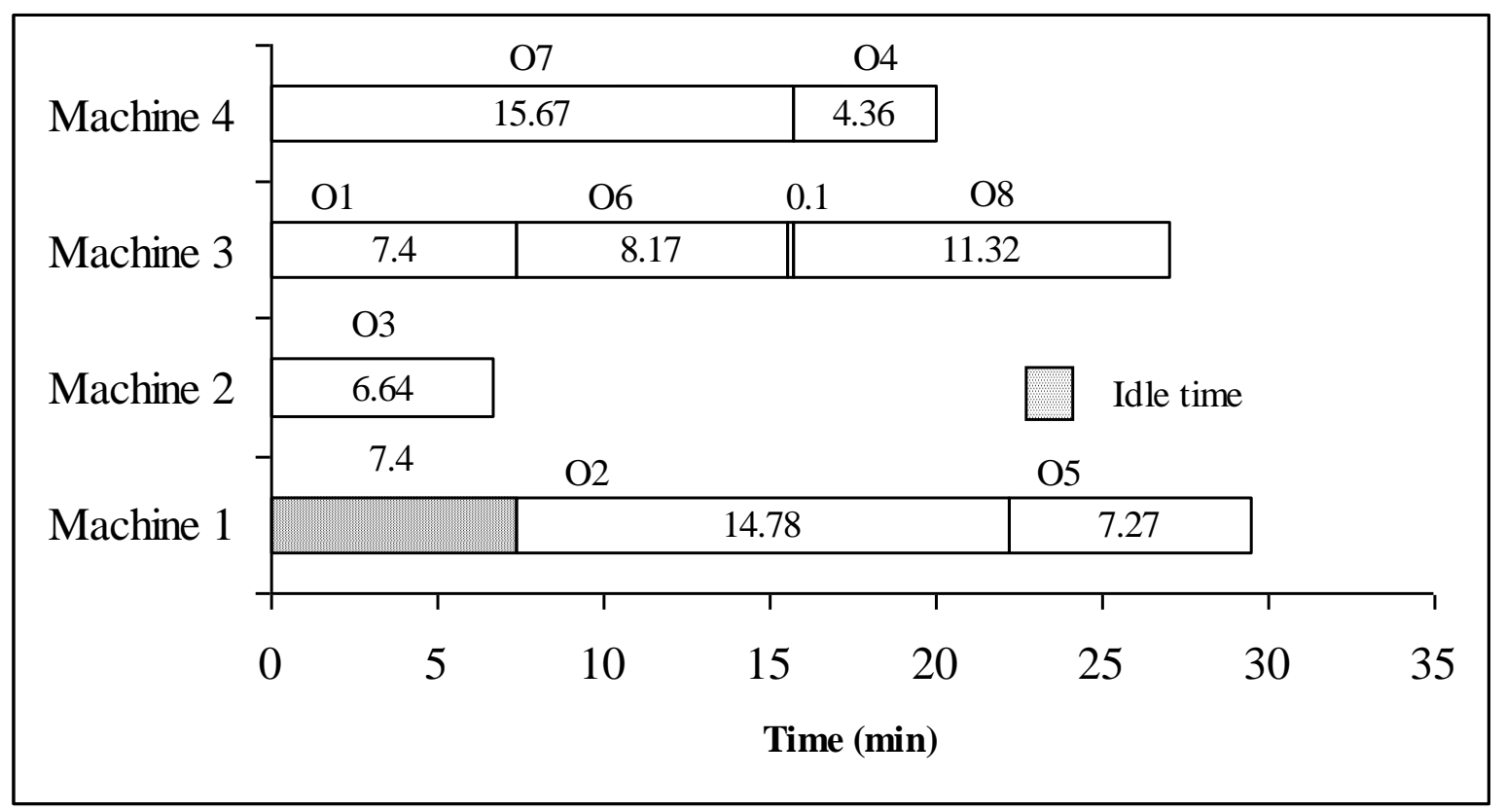


(b) Z2 without $\mathrm{C}_{\mathrm{QL}}$ (Best product sequence $\mathrm{X} 1 \mathrm{X} 4 \mathrm{X} 5 \mathrm{X} 2 \mathrm{X} 3$ )

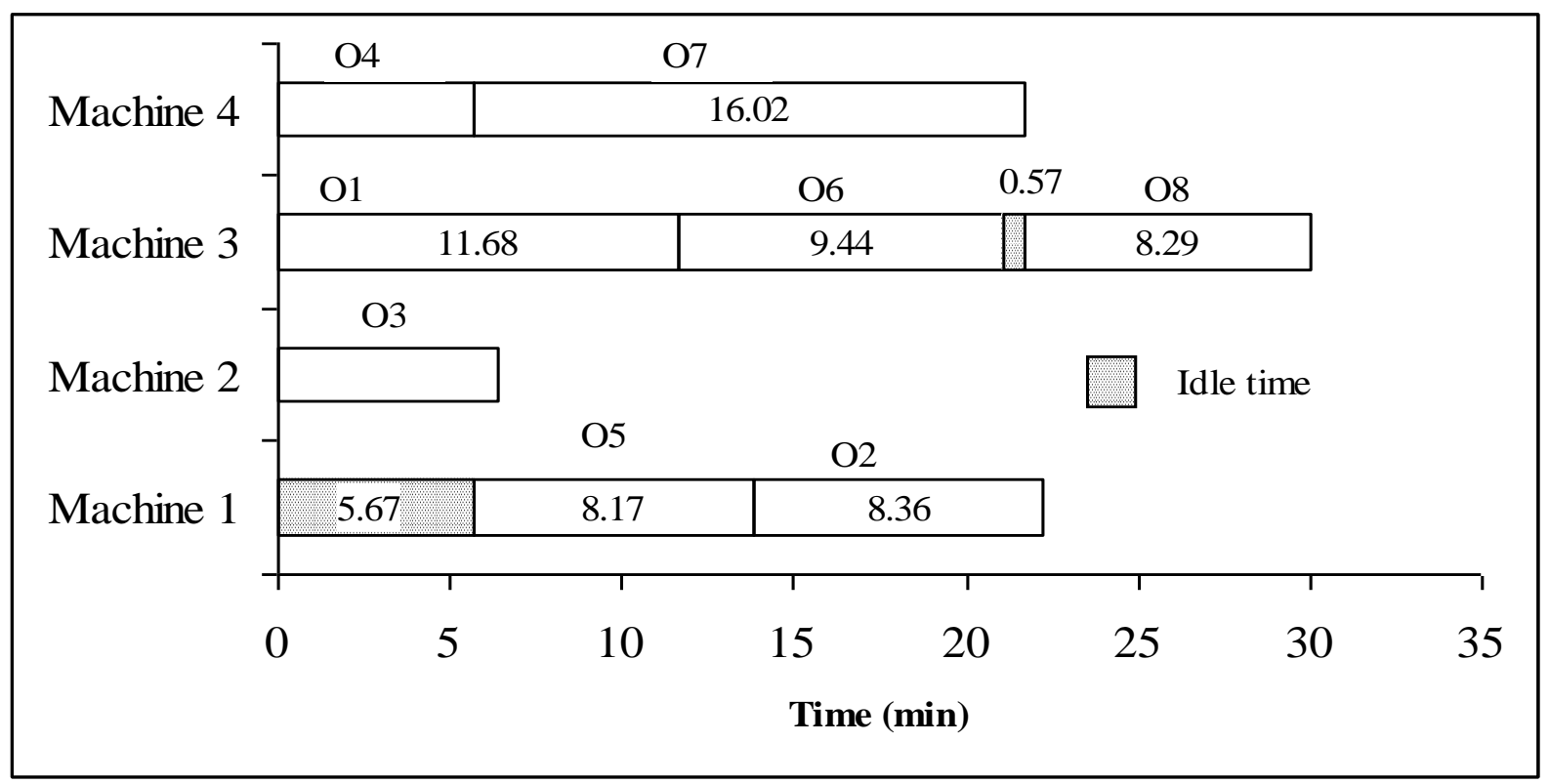

(c) $\mathrm{Z} 3$ without $\mathrm{C}_{\mathrm{QL}}$ (Best product sequence $\mathrm{X} 3 \mathrm{X} 1 \mathrm{X} 4 \mathrm{X} 5 \mathrm{X} 2$ )

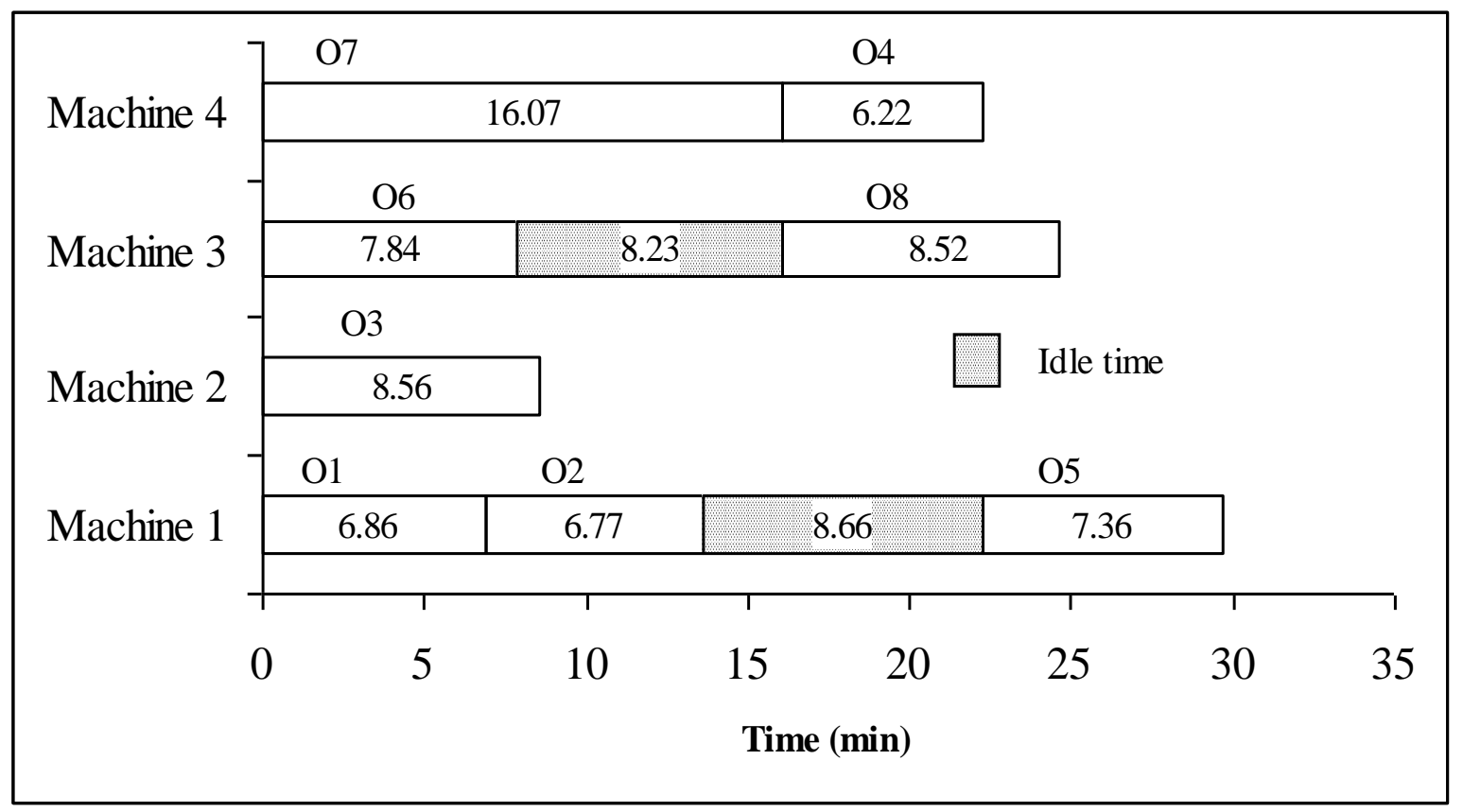

(d) Z1Z2 without $\mathrm{C}_{\mathrm{QL}}$ (Best product sequence $\mathrm{X} 1 \mathrm{X} 4 \mathrm{X} 5 \mathrm{X} 2 \mathrm{X} 3$ ) 


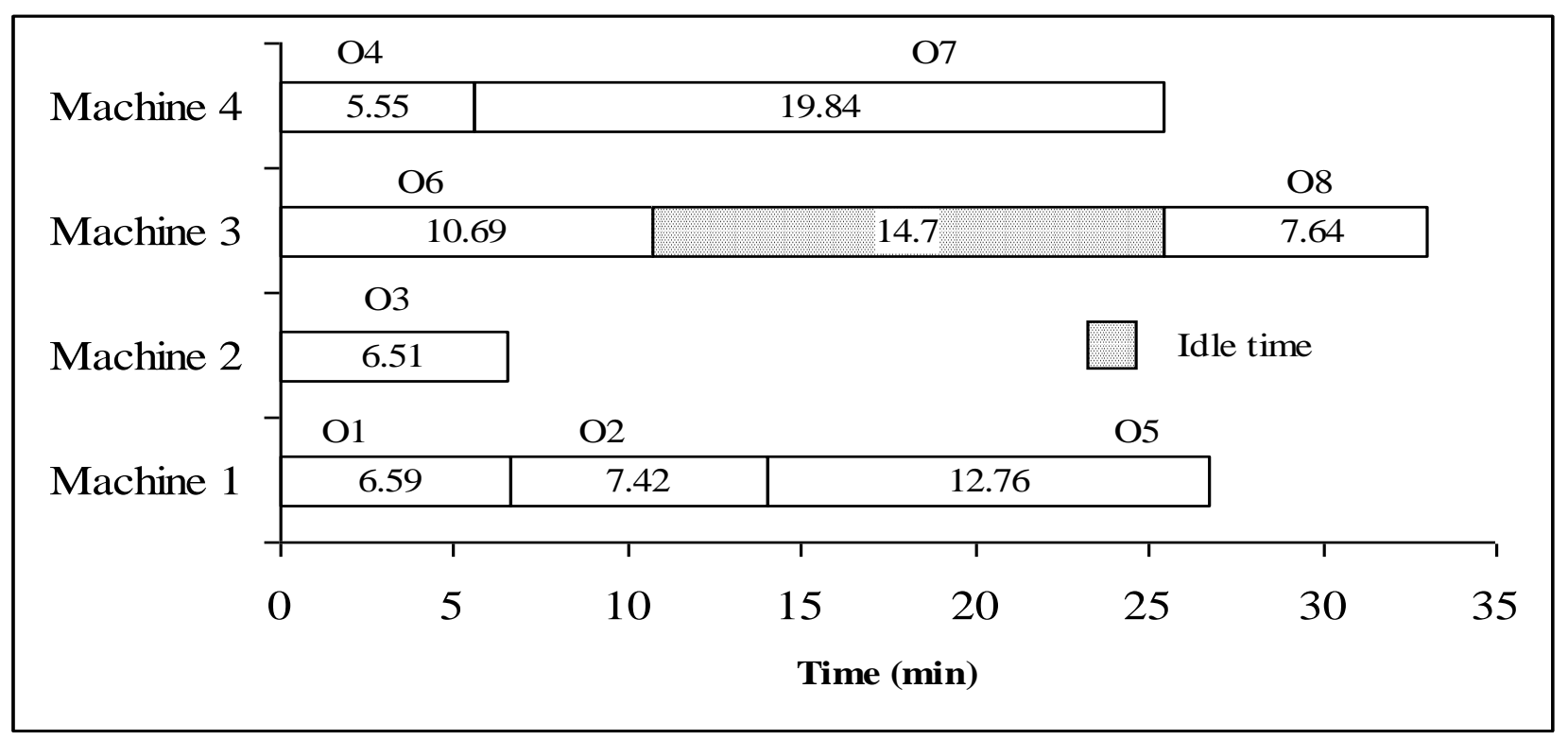

(e) Z1Z3 without $\mathrm{C}_{\mathrm{QL}}$ (Best product sequence $\mathrm{X} 1 \mathrm{X} 3 \mathrm{X} 4 \mathrm{X} 5 \mathrm{X} 2$ )

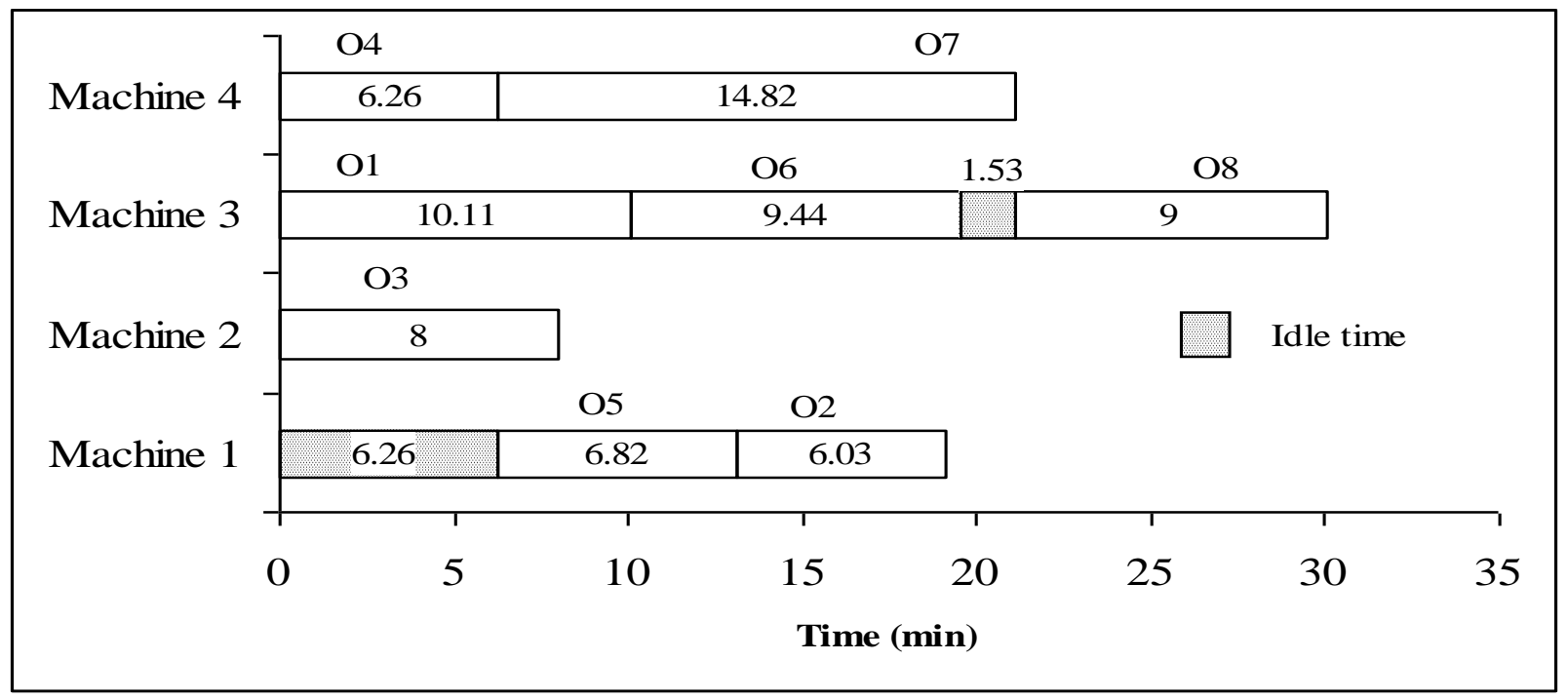

(f) Z2Z3 without $\mathrm{C}_{\mathrm{QL}}$ (Best product sequence $\mathrm{X} 3 \mathrm{X} 1 \mathrm{X} 4 \mathrm{X} 5 \mathrm{X} 2$ ) 


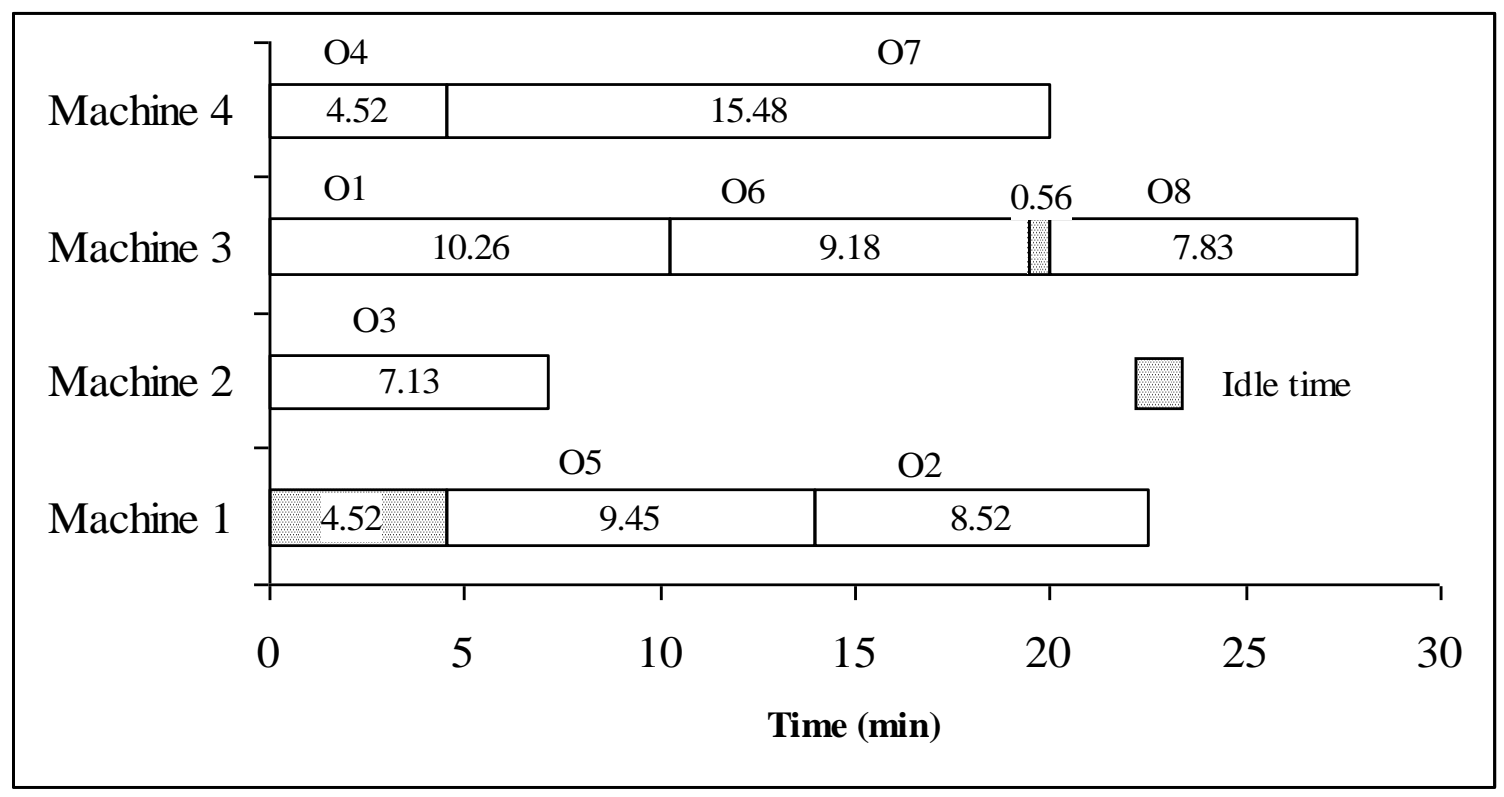

(g) Z1Z2Z3 without $\mathrm{C}_{\mathrm{QL}}$ (Best product sequence $\mathrm{X} 3 \mathrm{X} 1 \mathrm{X} 4 \mathrm{X} 5 \mathrm{X} 2$ ) 
Fig. 4: Machine idle time for the best product sequence of each objective function with $C_{Q L}$

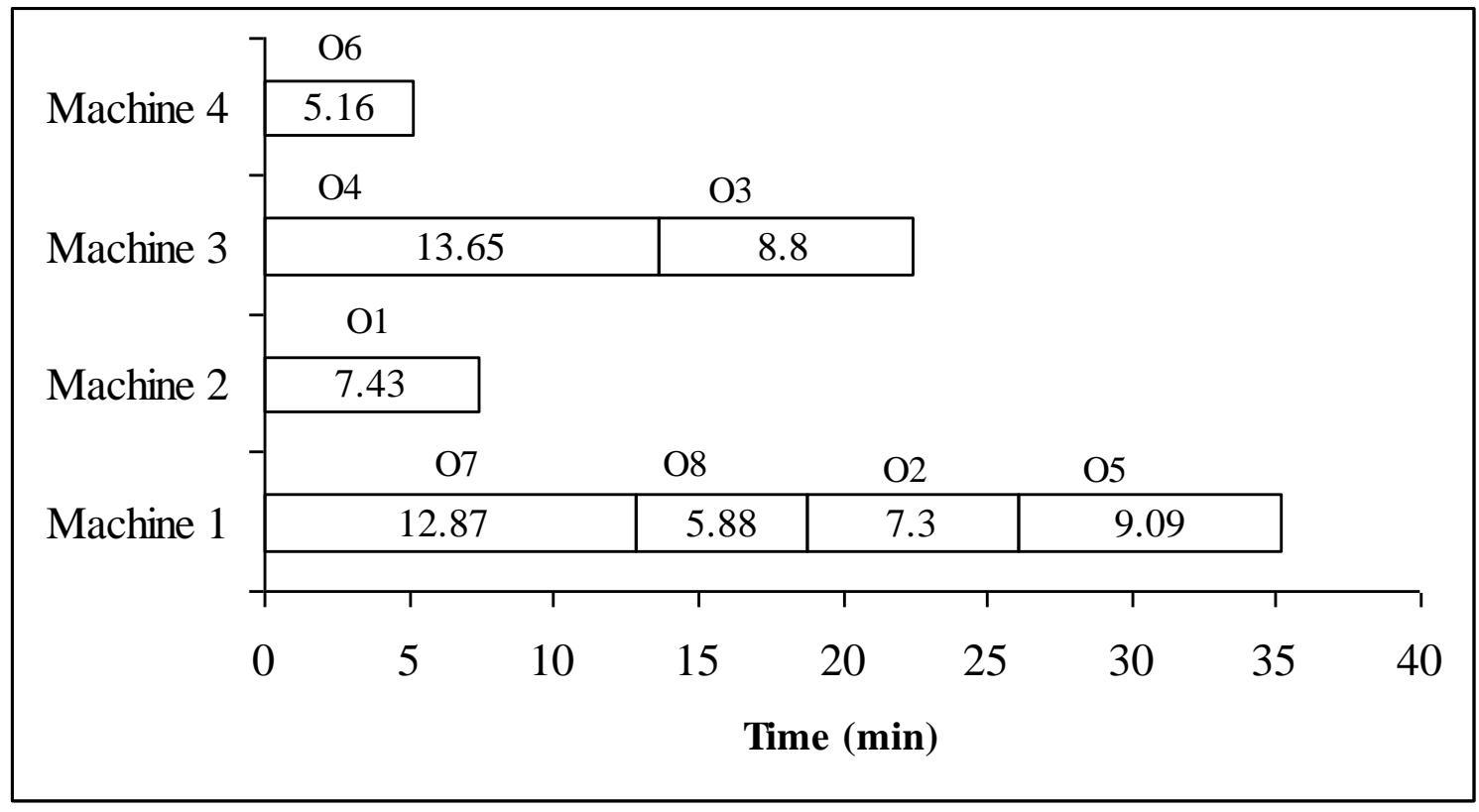

(a) $\mathrm{Z} 1$ with $\mathrm{C}_{\mathrm{QL}}$ (Best product sequence $\mathrm{X} 2 \mathrm{X} 1 \mathrm{X} 3 \mathrm{X} 4 \mathrm{X} 5$ )

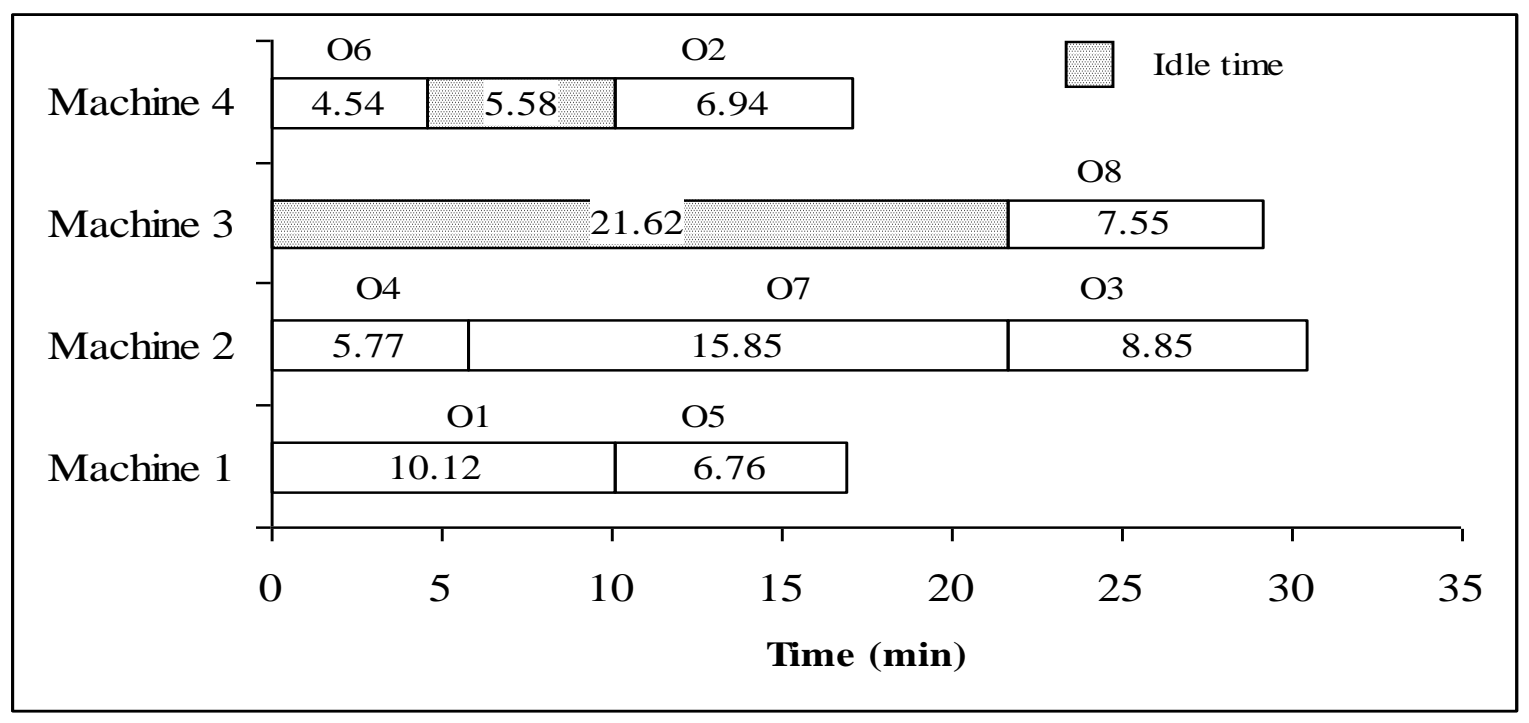

(b) Z2 with $\mathrm{C}_{\mathrm{QL}}$ (Best product sequence X5X1X3X2X4) 


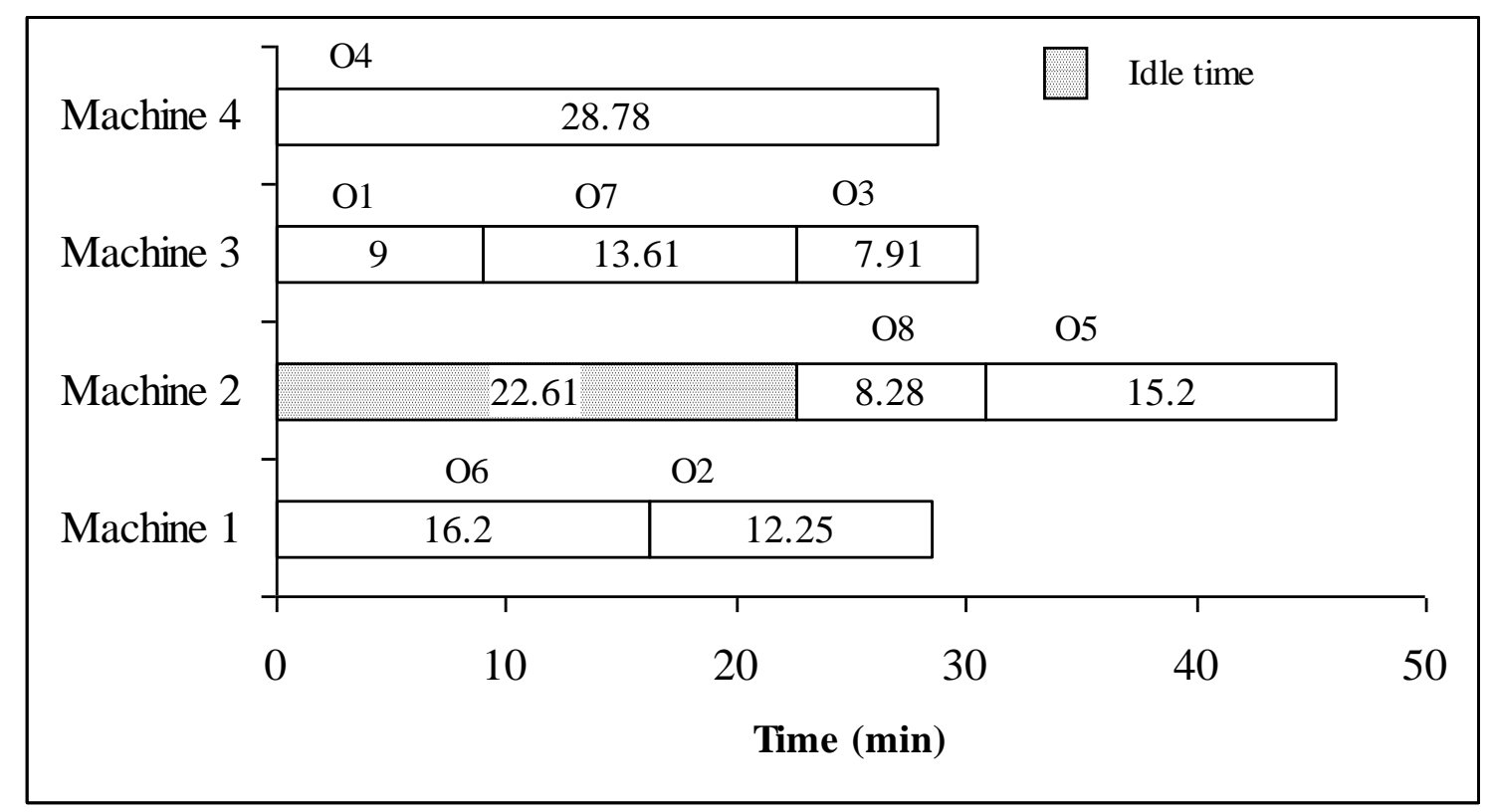

(c) $\mathrm{Z} 3$ with $\mathrm{C}_{\mathrm{QL}}$ (Best product sequence $\mathrm{X} 5 \mathrm{X} 1 \mathrm{X} 2 \mathrm{X} 4 \mathrm{X} 3$ )

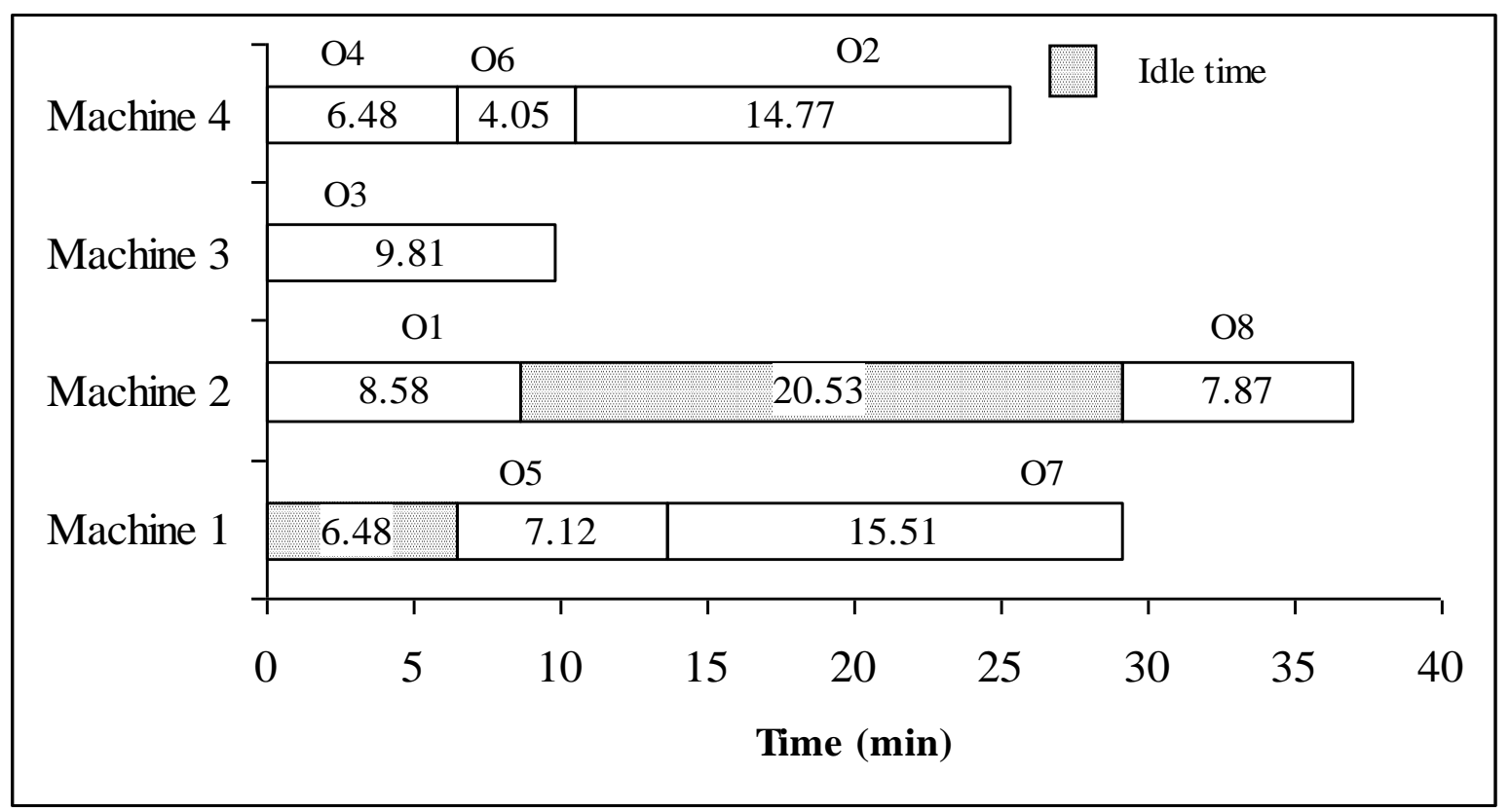

(d) Z1Z2 with $\mathrm{C}_{\mathrm{QL}}$ (Best product sequence X3X4X5X1X2) 


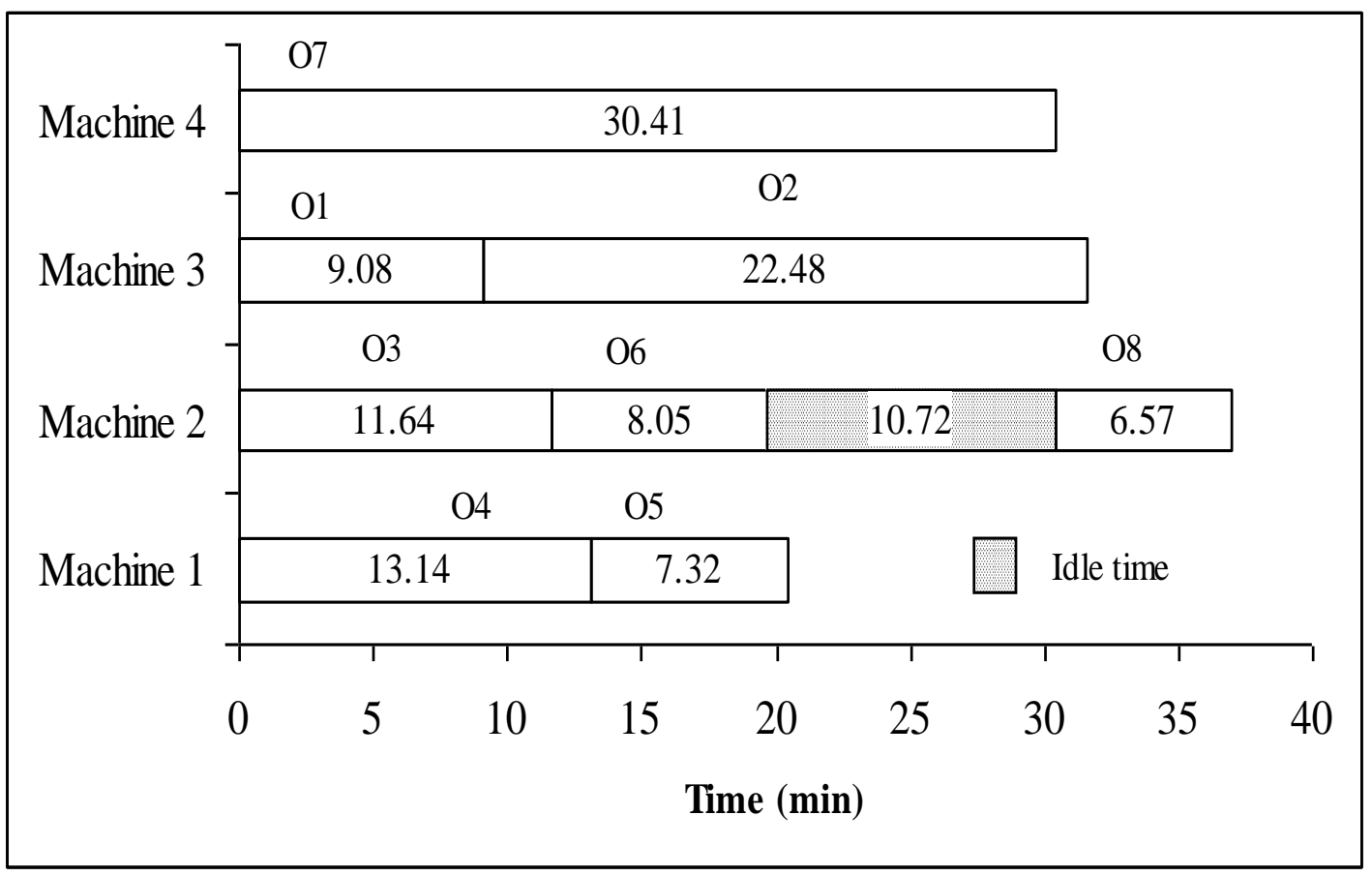

(e) Z1Z3 with $\mathrm{C}_{\mathrm{QL}}$ (Best product sequence X1X3X4X5X2)

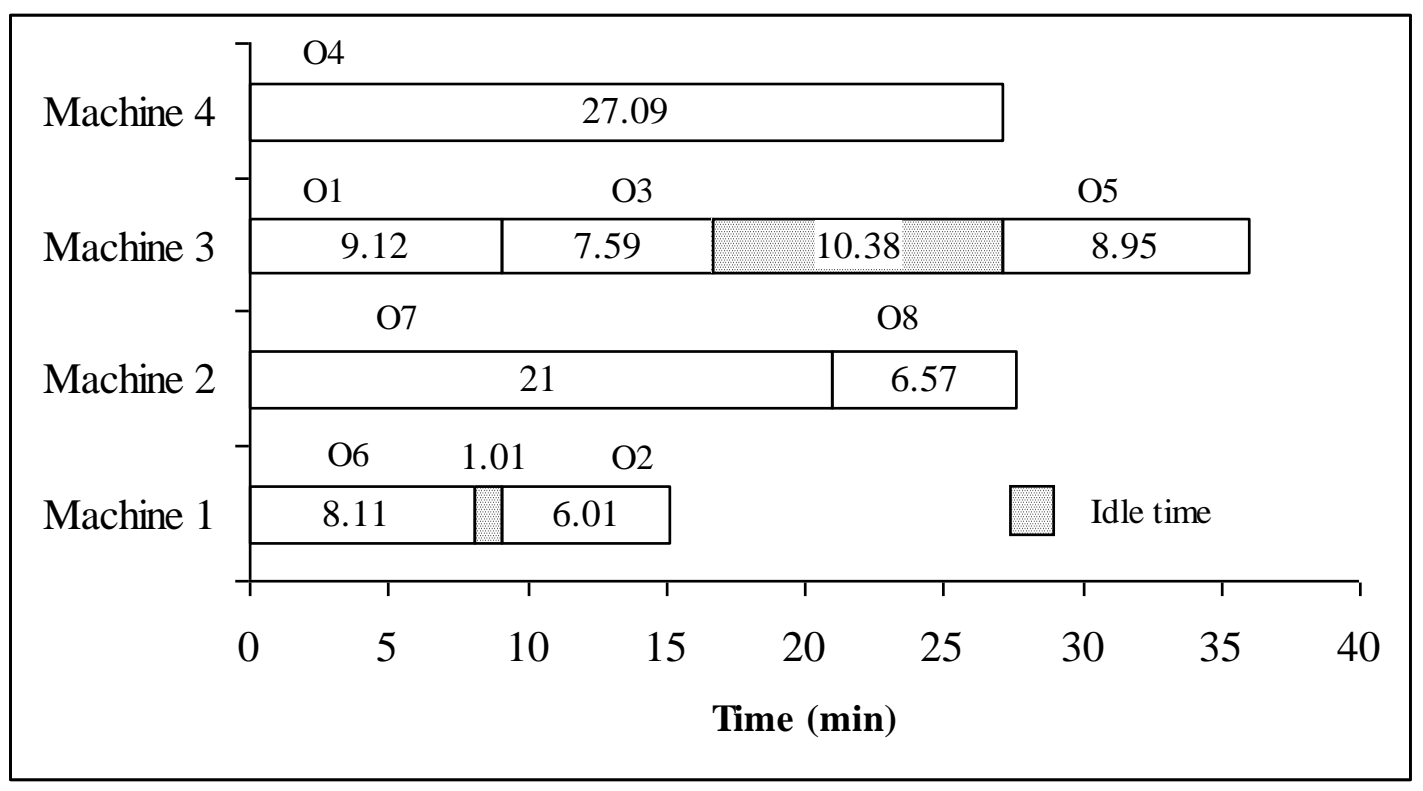

(f) Z2Z3 with $\mathrm{C}_{\mathrm{QL}}$ (Best product sequence $\mathrm{X} 2 \mathrm{X} 5 \mathrm{X} 1 \mathrm{X} 4 \mathrm{X} 3$ ) 


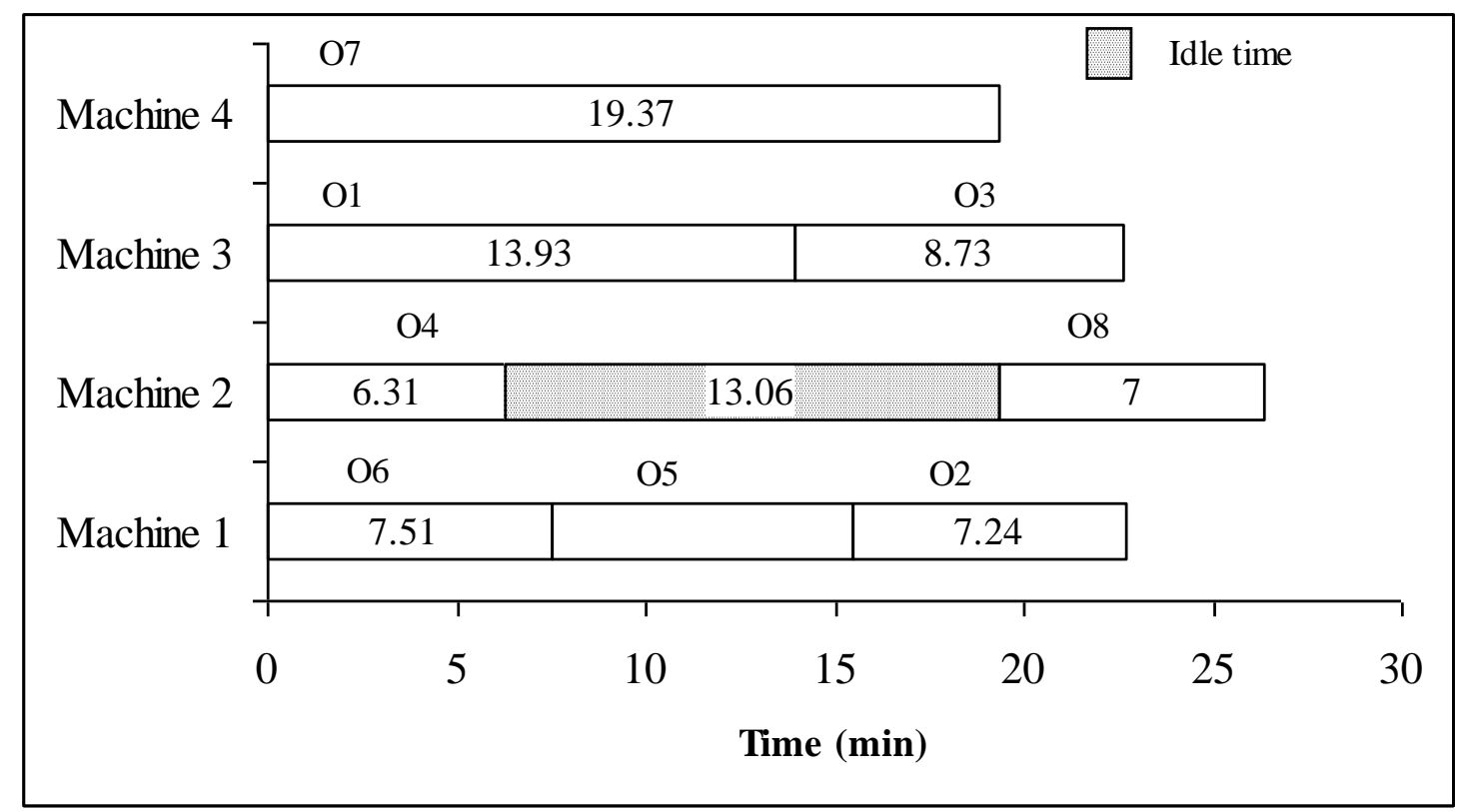

(g) Z1Z2Z3 with $\mathrm{C}_{\mathrm{QL}}$ (Best product sequence X5X3X2X1X4)

Fig. 5: Comparison of total machine idle time cost

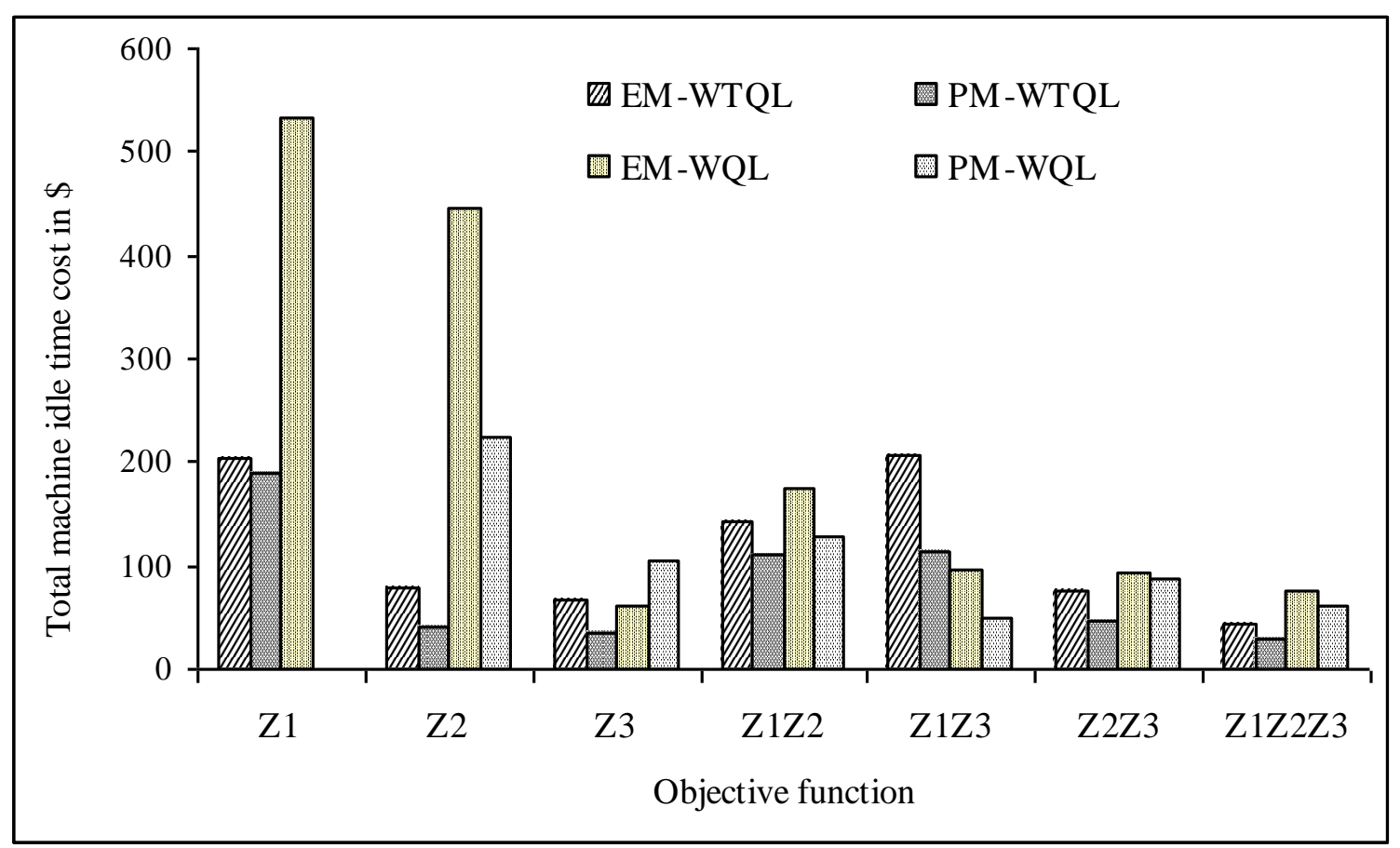


Fig. 6: Distribution of component's tolerance in each operation for $t_{y 1}$ without $C_{Q L}$

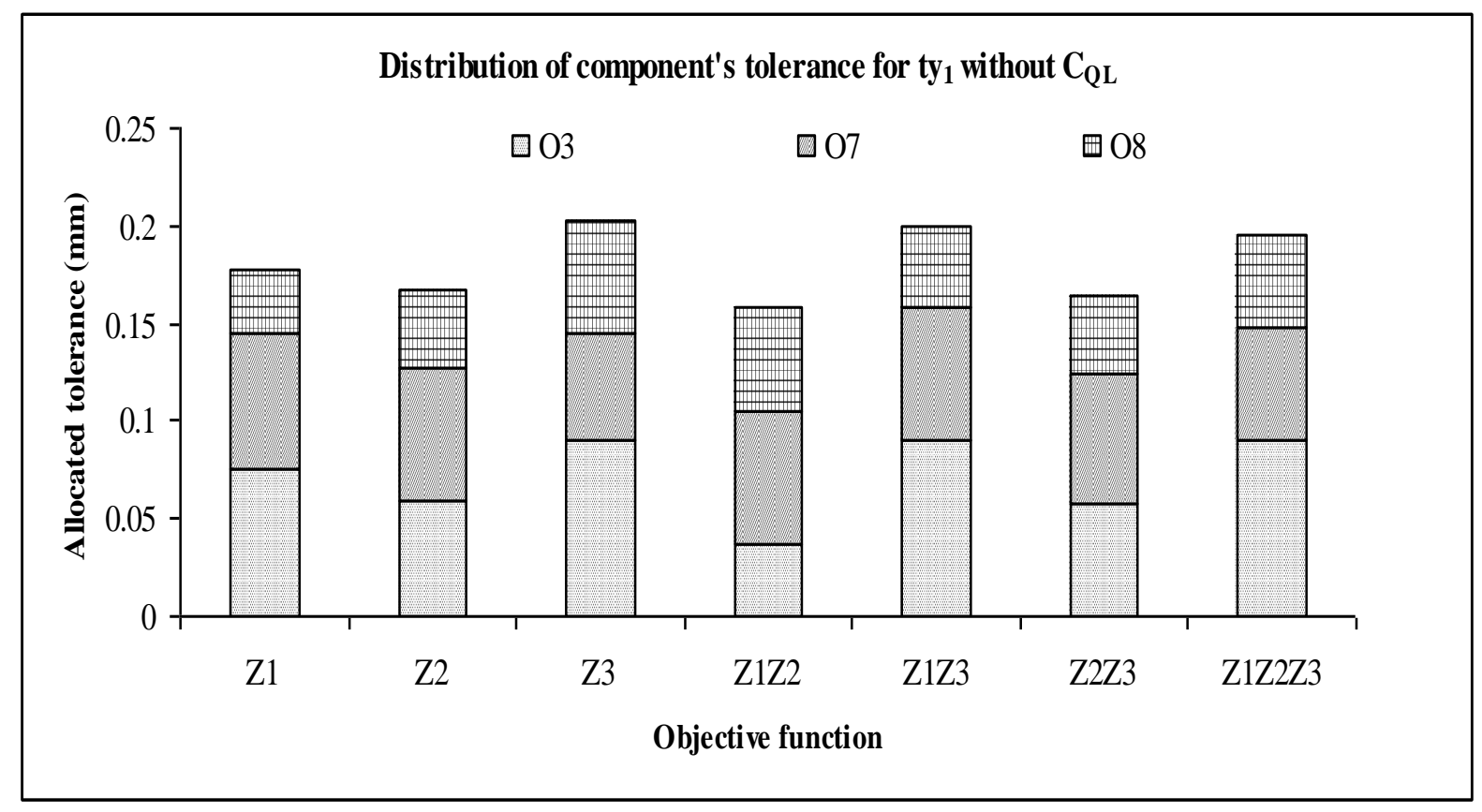

Fig. 7: Distribution of component's tolerance in each operation for $t_{y 2}$ without $C_{Q L}$

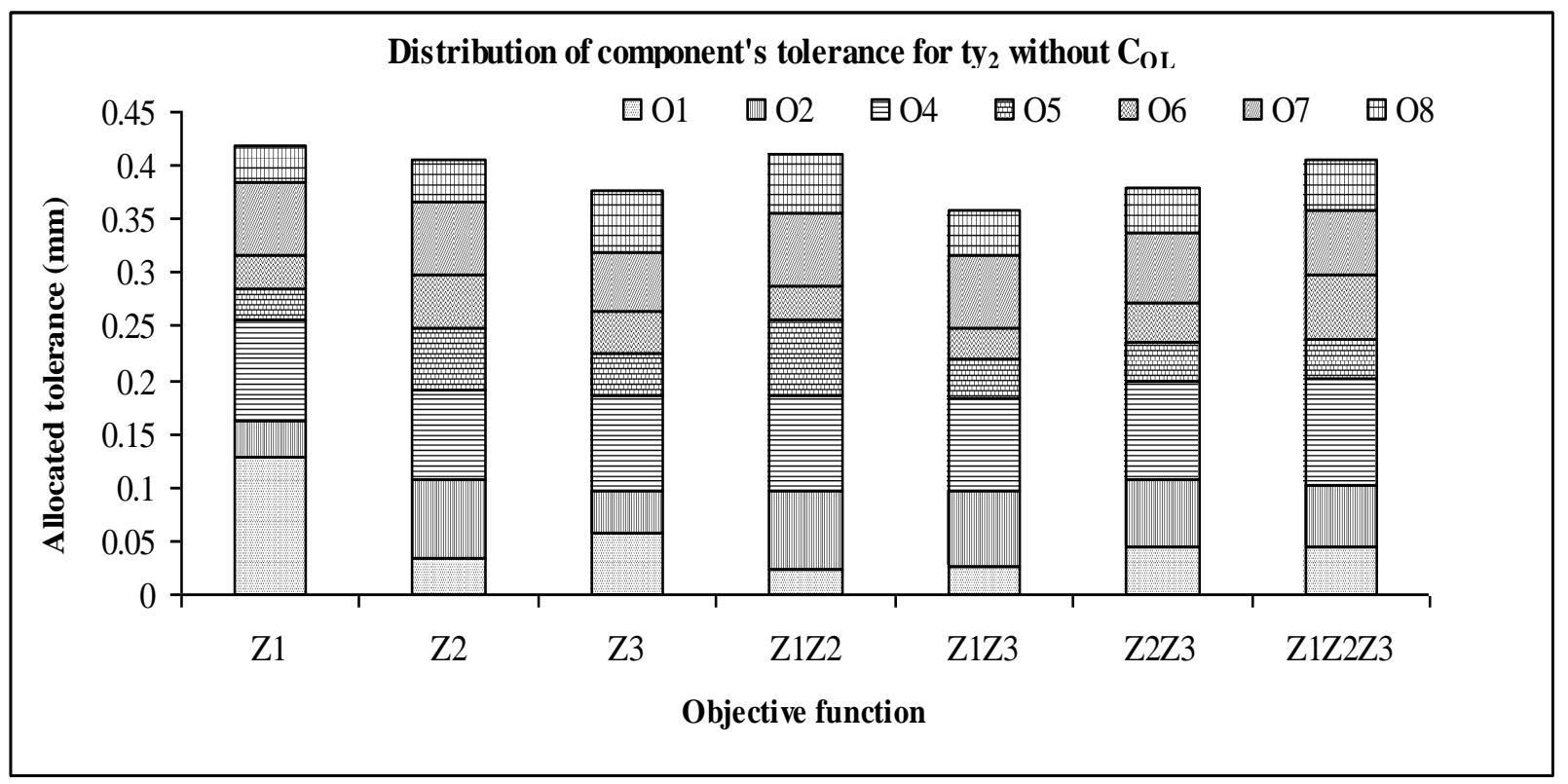


Fig. 8: Distribution of component's tolerance in each operation for $t_{y 1}$ with $C_{Q L}$

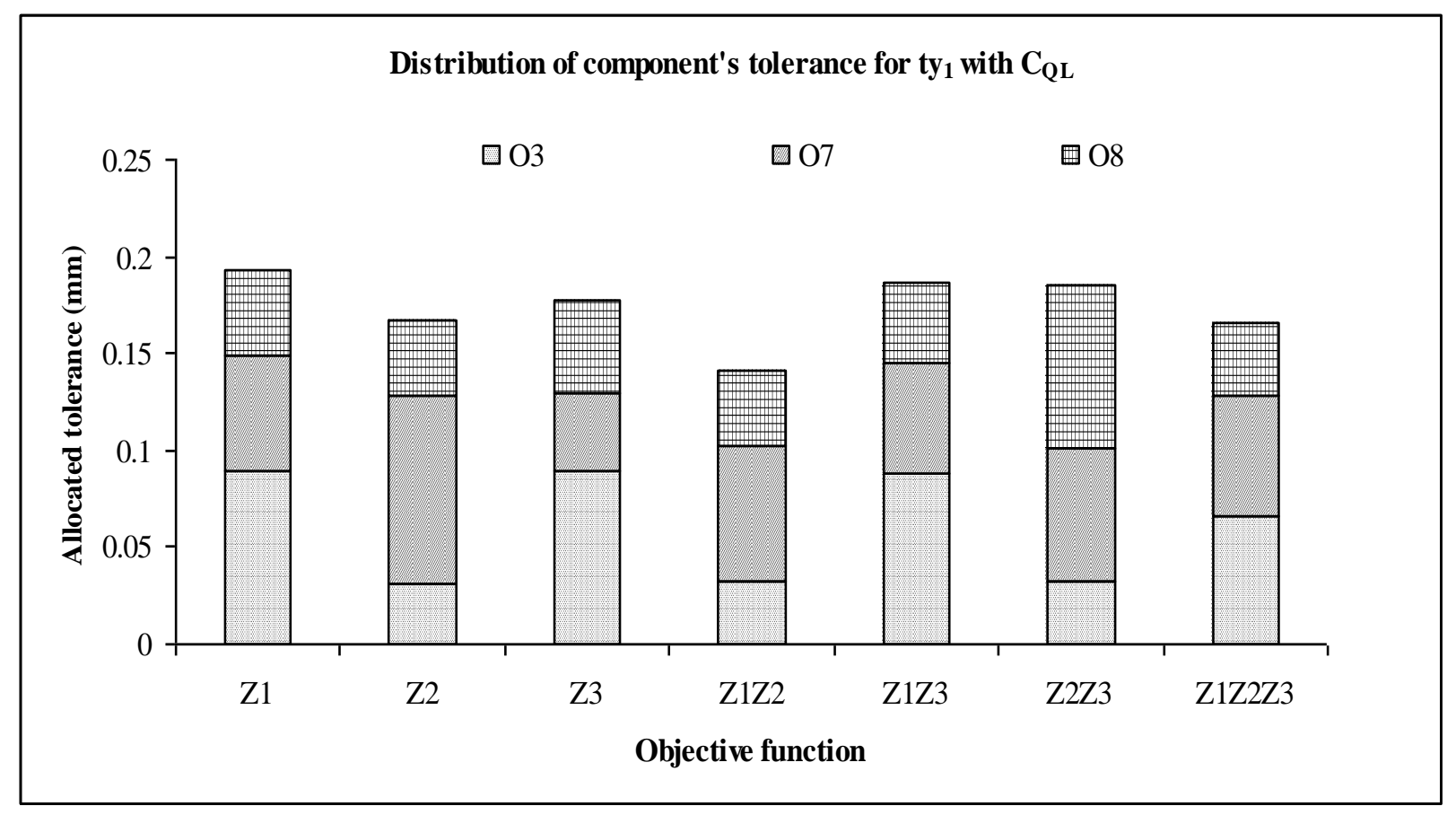

Fig. 9: Distribution of component's tolerance in each operation for $t_{y 2}$ with $C_{Q L}$

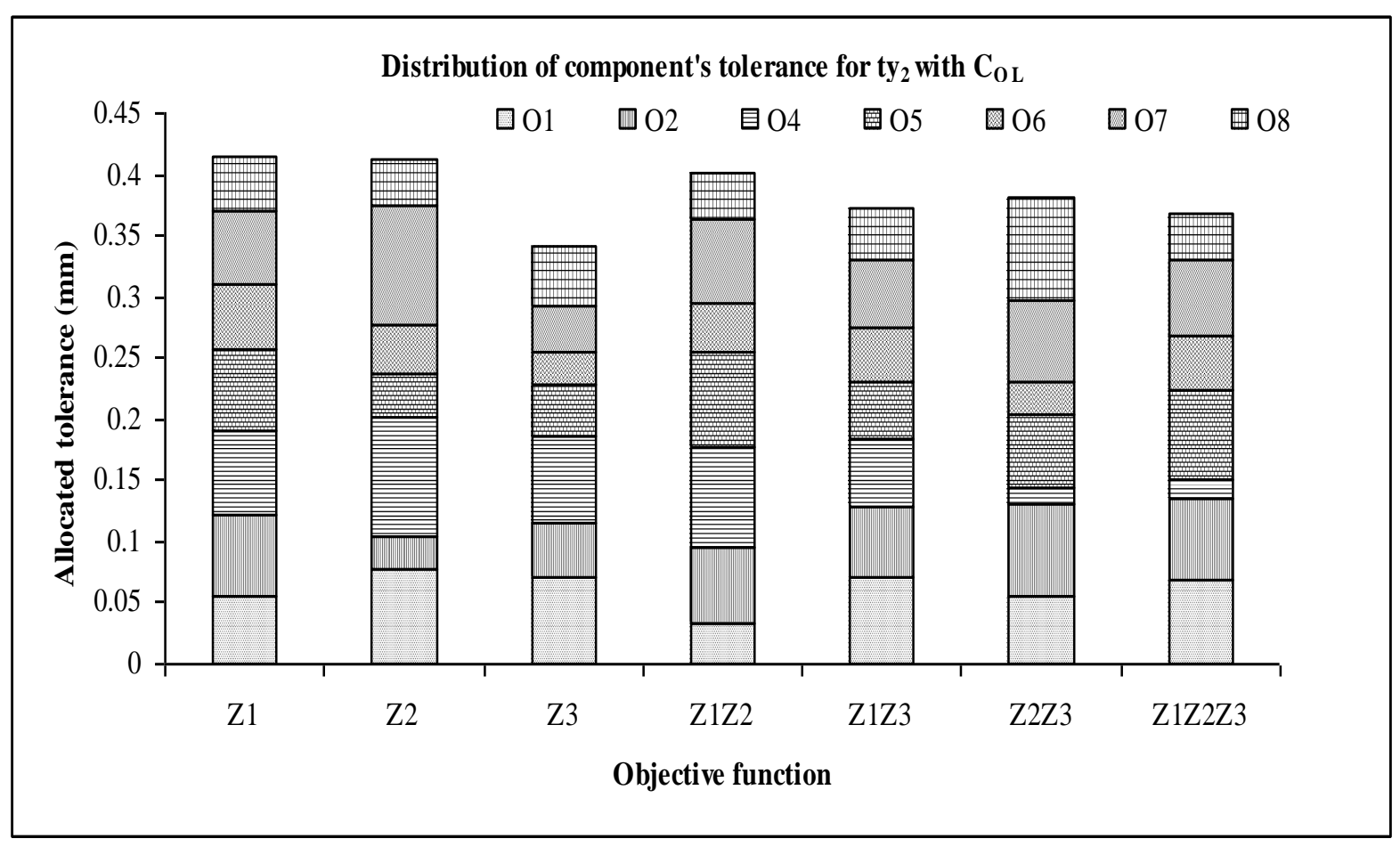


Fig. 10: Machining time of each operation with $C_{Q L}$

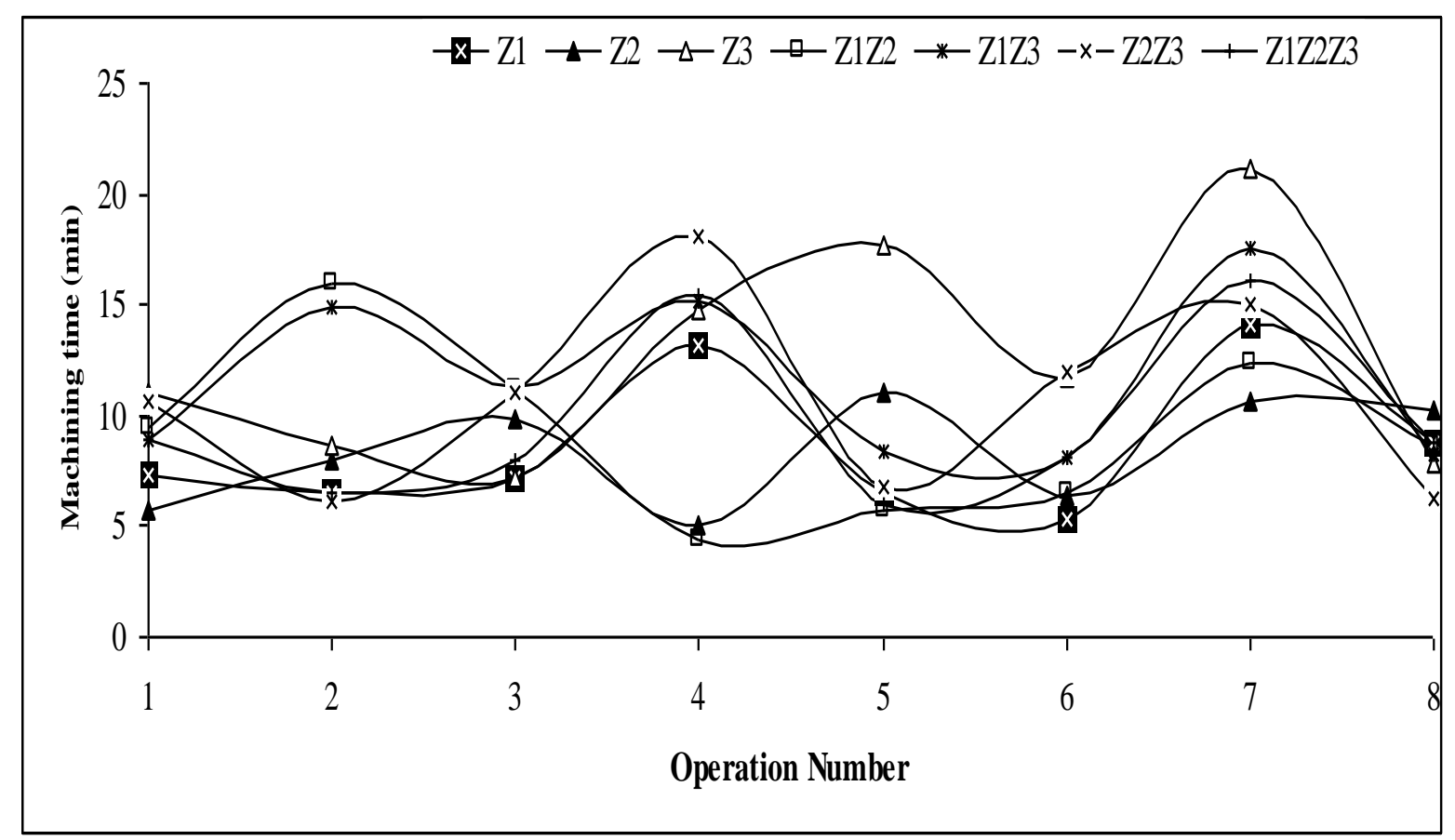

Fig. 11: Tolerance cost of each operation with $C_{Q L}$

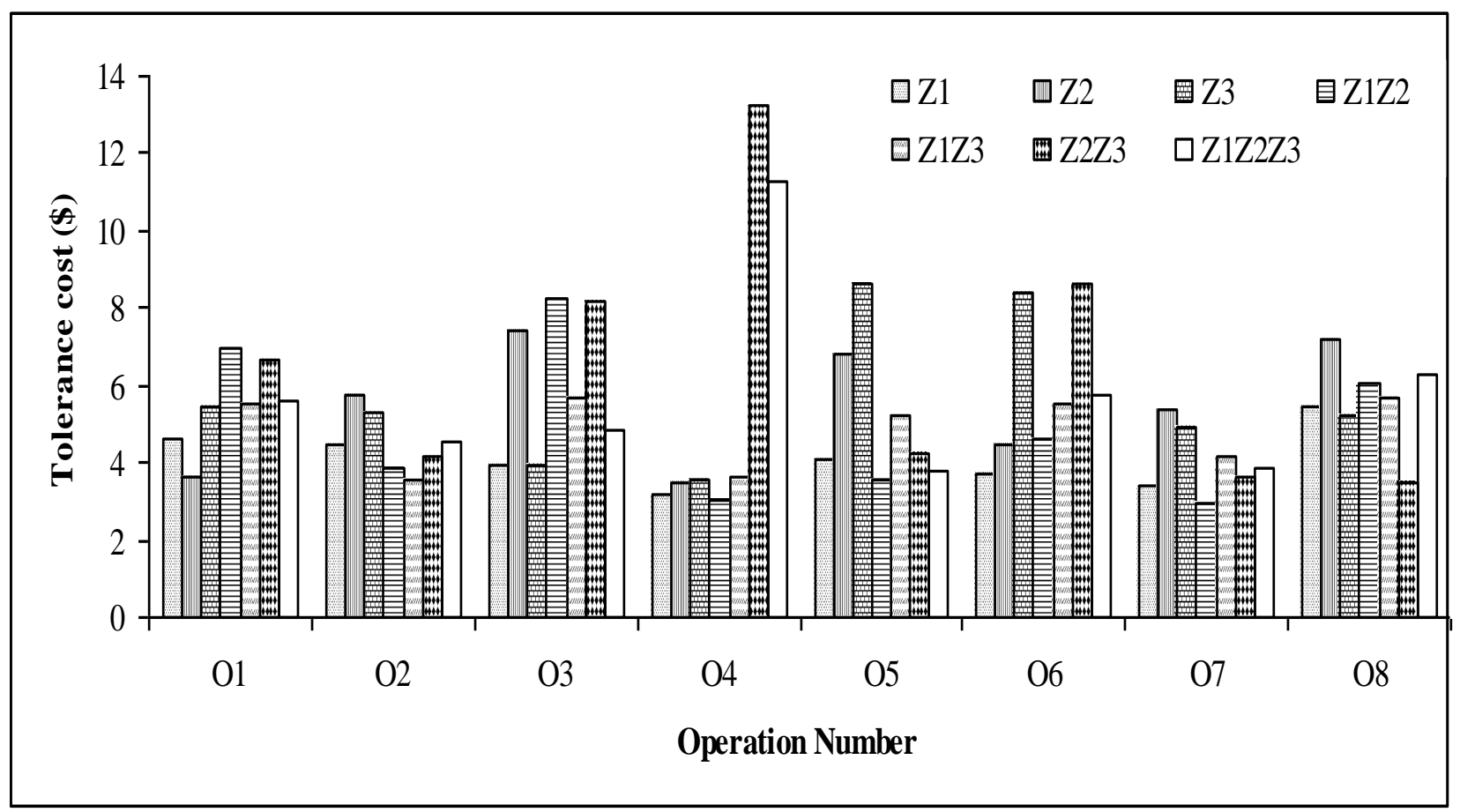


Fig. 12: Comparision of total cost between exisiting and proposed method

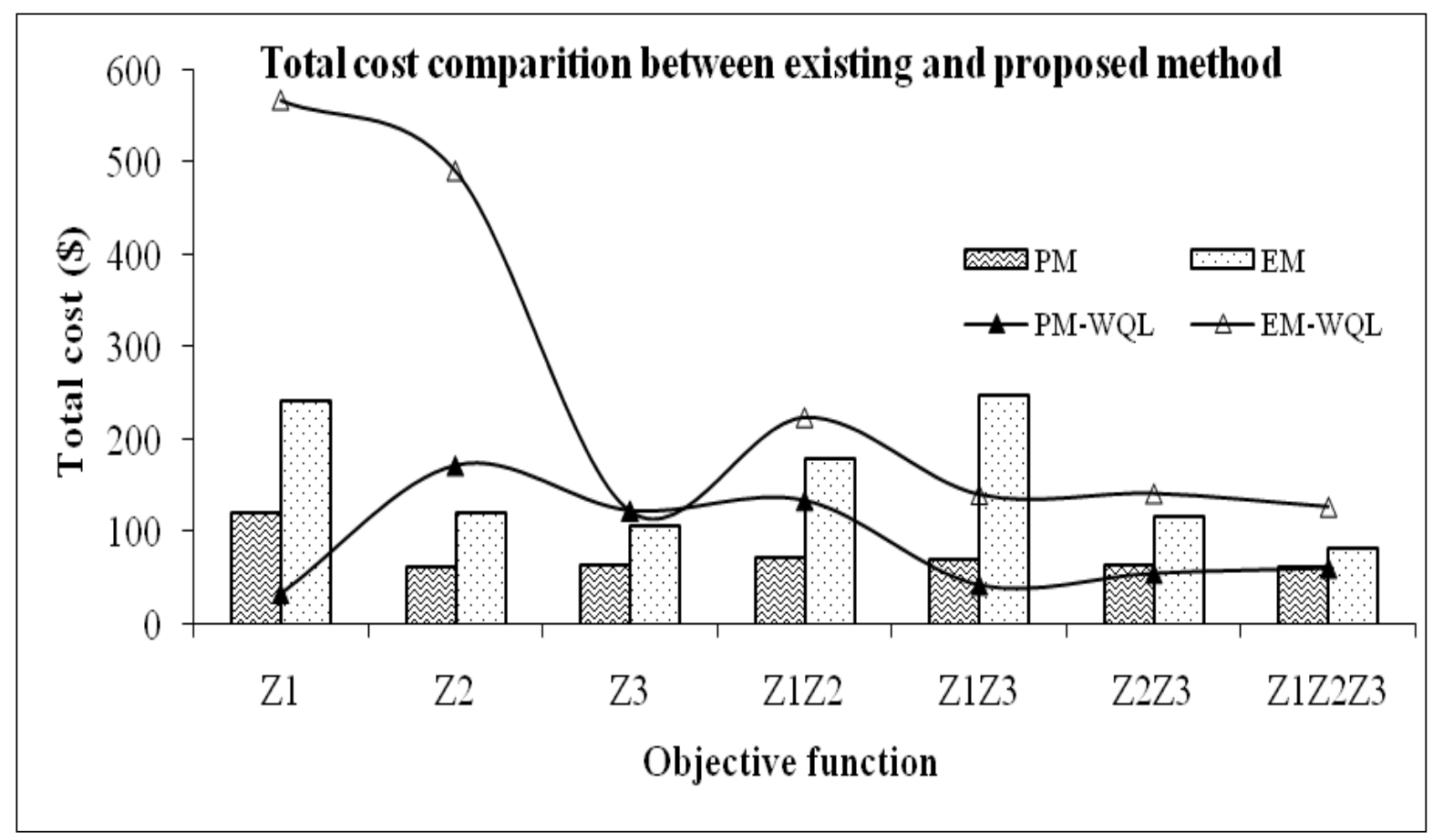

